LA-UR-99-5267

Approved for public release;

distribution is unlimited.

\title{
Title: $\mid$ Design and Analysis of the SNS CCL Hot Model Water Cooling System Using the SINDA/FLUINT Network Modeling Tool
}

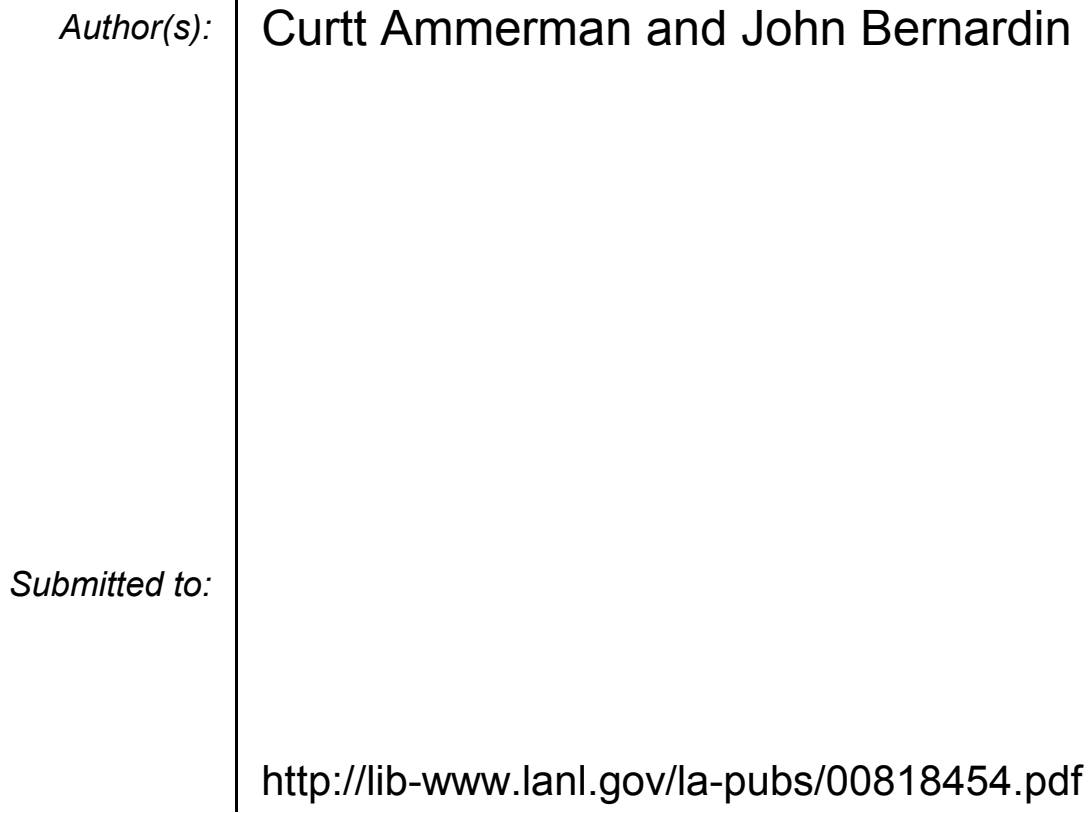

Los Alamos National Laboratory, an affirmative action/equal opportunity employer, is operated by the University of California for the U.S. Department of Energy under contract W-7405-ENG-36. By acceptance of this article, the publisher recognizes that the U.S. Government retains a nonexclusive, royaltyfree license to publish or reproduce the published form of this contribution, or to allow others to do so, for U.S. Government purposes. Los Alamos National Laboratory requests that the publisher identify this article as work performed under the auspices of the U.S. Department of Energy. Los Alamos National Laboratory strongly supports academic freedom and a researcher's right to publish; as an institution, however, the Laboratory does not endorse the viewpoint of a publication or guarantee its technical correctness. 


\title{
Design and Analysis of the SNS CCL Hot Model Water Cooling System Using the SINDA/FLUINT Network Modeling Tool
}

\author{
By \\ Curtt Ammerman and John Bernardin \\ Design Engineering Group \\ Engineering Science and Applications Division \\ Los Alamos National Laboratory
}

September 1, 1999 


\section{TABLE OF CONTENTS}

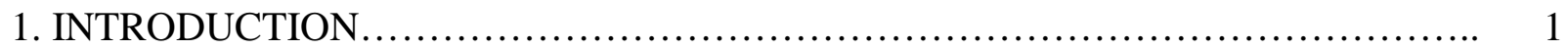

SNS CCL Hot Model and Water Cooling System................................ 1

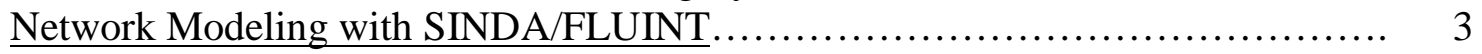

2. SINDA/FLUINT MODEL DEVELOPMENT .................................. 5

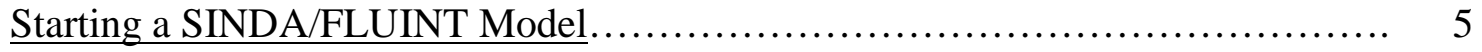

Fluid Submodels........................................................... 5

Incorporation of CFD Results...................................... 8

Pipe Lengths, Valves, Elbows, and Tees............................... 11

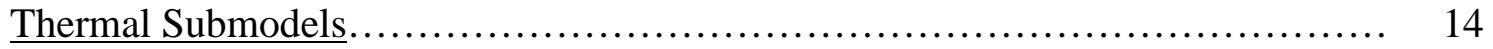

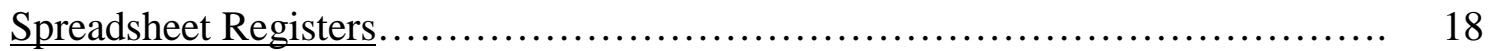

3. RUNNING SINDA/FLUINT .................................................... 19

Initial Setup and Execution.................................................... 19

Options Data........................................................... 19

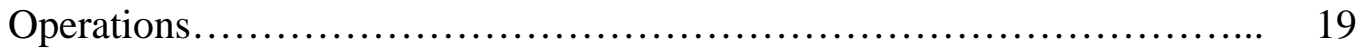

Global Control Data.................................................... 19

Fluid Property Data.................................................. 19

Registers ........................................................... 20

Thermal and Fluid Submodels...................................... 20

Utilities........................................................ 20

Save Everything................................................... 20

The Solver....................................................... 20

Run SINDA/FLUINT.............................................. 20

Exit Model..................................................... 21

Running Without Thermal Submodels..................................... 21

Using the Solver to Determine Valve Settings.................................. 21

Running Multiple Cases to Parametrically Vary Pipe Diameter.................... 23

4. MODELING RESULTS ........................................................ 25

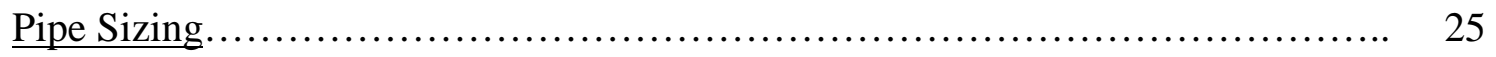

Heat Exchanger Modeling ................................................ 25

Pump Sizing .......................................................... 26

Temperature Control Trade Study ........................................ 26

Study of Cross-Flow Due to RF Window Location............................ 34

Transient Study to Determine Temperature Change vs. Time....................... 34

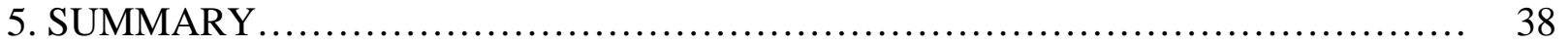

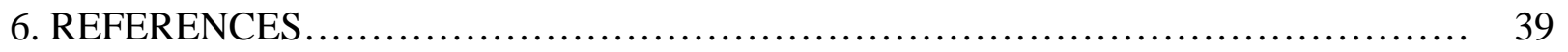

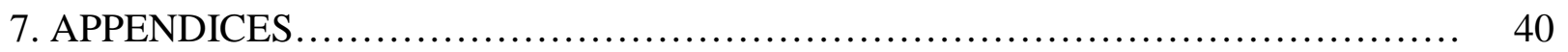

Appendix A. SINDA/FLUINT Spreadsheet Registers for Hot Model............... 40

Appendix B. Single-Phase Water Database.................................... 42 


\section{INTRODUCTION}

This report presents results for design and analysis of the hot model water cooling system for the Spallation Neutron Source (SNS) coupled-cavity linac (CCL). The hot model, when completed, will include segments for both the CCL and coupled-cavity drift-tube linac (CCDTL). The scope of this report encompasses the modeling effort for the CCL portion of the hot model. This modeling effort employed the SINDA/FLUINT network modeling tool. This report begins with an introduction of the SNS hot model and network modeling using SINDA/FLUINT. Next, the development and operation of the SINDA/FLUINT model are discussed. Finally, the results of the SINDA/FLUINT modeling effort are presented and discussed.

\section{SNS CCL Hot Model and Water Cooling System}

A drawing of the SNS hot model is shown in Figure 1. The first three segments (from left to right) are the CCDTL portion of the hot model. The next four segments are the CCL portion. The design effort described in this report is only for the water cooling system attached to the CCL segments. Within the CCL portion of the hot model, there are one full and one partial low-energy segment number 183, and one full and one partial high-energy segment number 347. (The RF power for the CCL hot model is fed into full segment 183.) Each segment is composed of accelerating cavities and coupling cells. The partial segments each contain $2 \frac{1 / 2}{2}$ cavities and 2 coupling cells. The full segments each contain 10 cavities and 10 coupling cells. The copper plates that form these cavities and coupling cells are assembled such that the coupling cells alternate between an upward and a downward orientation.

Figure 2 shows the flow manifolds and water cooling channels within the CCL RF structure. The coupling cells are each cooled by a single flow channel that is $6.35 \mathrm{~mm} \times 2.0 \mathrm{~mm}$ in crosssection and is approximately $0.6-\mathrm{m}$ long. External manifolds supply the water to this channel. The accelerator cavities are cooled by water flowing through both 4-channel and 1-channel passages. The 4-channel passages are $7.5 \mathrm{~mm} \times 2.0 \mathrm{~mm}$ and range in length from approximately 0.5 to $0.68 \mathrm{~m}$. The 1 -channel passage splits into upper and lower branches. To aid in equalizing the flow between these two branches, the lower (longer) branch is 1-mm deeper than the upper branch. The geometry, therefore, is $7.5 \mathrm{~mm} \times 2.0 \mathrm{~mm}$ by approximately $0.2-\mathrm{m}$ long for the upper branch and $7.5 \mathrm{~mm} \times 3.0 \mathrm{~mm}$ by approximately $0.6-\mathrm{m}$ long for the lower branch. These cavity cooling channels are supplied by two, 1-inch-diameter, internal manifolds that run the entire length of each segment. Each supply manifold is paired with a 1-inch-diameter return manifold. The cavity cooling channels in the upward-oriented plates are serviced by 1 pair of manifolds and those oriented downward are serviced by the remaining pair (also shown in Figure 2). The water in each of these pairs of manifolds flows in opposite directions (counter flow) to provide for a more uniform temperature within the structure.

The preliminary design requirements for the water cooling system are shown in Table 1 [1]. The hot model water cooling system will remove waste heat generated from the RF fields in the accelerator cavities. Each cavity will generate approximately $2 \mathrm{~kW}$ of waste heat resulting in a total heat removal requirement of approximately $50 \mathrm{~kW}$. In addition, this cooling system will aid in tuning the RF fields within these cavities. The nominal cooling water temperature rise requirement of $3.1^{\circ} \mathrm{C}$ sets the total water flow rate for the CCL hot model to approximately 61 $\mathrm{gpm}$. This flow rate was increased to $65 \mathrm{gpm}$ to provide for flow through the coupling cells, 
(note: see figures at end of file) 
which are expected to dissipate minimal amounts of heat. By varying the cooling water temperature by $\pm 7.5^{\circ} \mathrm{C}$, the resonance frequency within the cavity assembly can be changed by $\pm 100 \mathrm{kHz}$ due to thermal expansion or contraction of the structure. Waste heat from the hot model will be removed from the water cooling system using a heat exchanger connected to a secondary cooling loop containing a water chiller.

Table 1. SNS CCL Water Cooling System Requirements [1].

\begin{tabular}{|l|l|}
\hline \multicolumn{1}{|c|}{ Parameter } & \multicolumn{1}{|c|}{ Value } \\
\hline - Nominal heat load per cavity & $\bullet 2 \mathrm{~kW}$ \\
- Nominal heat load for 25 cavities & $\bullet 50 \mathrm{~kW}$ \\
\hline - Nominal water temperature rise per cavity & $\bullet 3.1^{\circ} \mathrm{C}$ \\
\hline - Range of frequency control & $\bullet \pm 100 \mathrm{kHz}$ \\
- Frequency shift per change in cavity water inlet temperature & $\bullet 13.3 \mathrm{kHz} / 1^{\circ} \mathrm{C}$ \\
\hline - Cavity water inlet temperature & $\bullet 24.9^{\circ} \mathrm{C}\left(76.8^{\circ} \mathrm{F}\right)$ \\
- Temperature range of water & $\bullet \pm 7.5^{\circ} \mathrm{C}\left( \pm 14^{\circ} \mathrm{F}\right)$ \\
\hline
\end{tabular}

\section{Network Modeling with SINDA/FLUINT}

SINDA/FLUINT Version 4.1 [2] was chosen to perform the design and analysis of the CCL hot model water cooling system. The use of computational fluid dynamics (CFD) is desirable for designing components of the cooling system, such as the cavity cooling channels. CFD is not appropriate, however, for the design of the overall water cooling system. CFD is inappropriate because the cooling system flow domain is too large to be solved with CFD and the level of detail provided by CFD is not necessary for a successful design. SINDA/FLUINT is the ideal tool for this task because it is a comprehensive equation solver (circuit or network analogy using lumped parameters) for analyzing complex thermal/fluid systems. With a network model, the flowloop can be represented by a series of junctions, paths, and sources. This representation enables the mass, momentum, and energy balance equations to be easily formulated for use with the internal equation solver.

SINDA/FLUINT (systems improved numerical differencing analyzer with fluid integrator) is the combination of SINDA, a thermal network analyzer, and FLUINT, a fluid network analyzer. SINDA/FLUINT incorporates the use of separate thermal and fluid submodels for improved organization. SINDA/FLUINT provides for multiple fluid flow networks with coupled heat transfer solutions. With this capability, separate flow loops can be generated for both the primary cooling loop and the secondary chiller loop. In addition, thermal submodels can be generated and coupled with the fluid submodels to simulate the heat generated from the RF structure. SINDA/FLUINT is driven with a graphical user interface program called SinapsPlus so that coupling of the thermal and fluid submodels is seamless.

SINDA/FLUINT includes general pump, valve, and pipe models and can calculate pressure drop as a function of flow rate throughout a flowloop. SINDA/FLUINT employs tabulated working fluid properties so that realistic, temperature-varying water data are used. It can also generate 
both steady state and transient solutions and can perform goal-seeking (using the "solver" option) to eliminate the need to run several trial-and-error solutions.

SINDA/FLUINT was used in order to obtain the following desired objectives:

- size pipe diameters throughout the CCL cooling system,

- size the heat exchanger,

- calculate pressure drops throughout the system to enable pump sizing,

- investigate heat removal and propose a temperature control methodology,

- examine the effects of manifold cross-flow, and

- perform transient temperature changes within the RF structure. 


\section{SINDA/FLUINT MODEL DEVELOPMENT}

This section describes the development of the SINDA/FLUINT model used to simulate the CCL hot model cooling system. The general layout of the model is discussed including the separate fluid and thermal submodels, inclusion of valves and fittings, and incorporation of CFD flow and pressure drop results for the cavity cooling channels. The modeling was performed using both steady-state and transient operating conditions.

\section{Starting a SINDA/FLUINT Model}

There are different ways to start building a SINDA/FLUINT model using SinapsPlus. This section describes one of these methods. 1) Create a directory in which to work and copy the 'startPlus.im' image into the directory (this file can be found in the /Cullimore and Ring/SinapsPlus/Images directory). 2) Launch the model by double-clicking on the image icon and the 'model browser' window will appear. 3) Select 'add model' from the pull-down menu and type in the name of your model. 4) Double-click on the model name and you will get the model 'control panel' from which you can go on to create both thermal and fluid submodels.

\section{Fluid Submodels}

Two fluid submodels were included in the baseline SINDA/FLUINT model. These submodels represent the primary cooling loop (labeled 'flowloop') and the secondary chiller loop (labeled 'coldloop'). Diagrams of the primary and secondary loops are shown in Figures 3 and 4, respectively. To edit a fluid submodel, choose 'fluid submodels' from the model 'control panel,' and double-click on submodel name of interest. A submodel 'control panel' will appear. From this panel, select 'edit network.' For the baseline run for each of the fluid submodels used in this study, none of the options on the submodel 'control panels' were used. (In Section 4.0, the use of the 'array data' option will be discussed in relation to the input of the pump curve.)

Approximately 225 nodes and 310 paths were used to model the primary cooling loop shown in Figure 3. (The secondary chiller loop shown in Figure 4 is similar to the primary flow loop except with fewer nodes and paths.) All but one of the nodes were modeled as junctions (represented by the ovals). A junction has zero volume, hence incoming and outgoing flows must always balance. In addition, a plenum node (represented by the triangle) was used to provide a reference pressure, which is required for steady-state operation. A plenum has infinite volume and is used as a pressure boundary condition.

Four different types of paths were used in this fluid submodel: tubes, control valves, loss connectors, and a constant-volume-flow connector. Tubes are used to model pipes of varying length and diameter. SINDA/FLUINT calculates frictional pressure drop through tubes. Control valves are used to simulate real valves in the system. SINDA/FLUINT calculates the flow resistance through a control valve with a user-supplied loss factor and valve flow area. Loss connectors are similar to control valves and require similar inputs. In the present case, the loss connector was used to model generic losses in the loop such as a filter, expansion tank, etc. The constant-volume-flow connector was used to simulate the pump. This connector provides a constant volumetric flow rate regardless of the flow resistance downstream. Using this type of connector as the pump is a convenient means of determining the loop pressure drop when a flow rate is specified, as in the case of the hot model. In a fluid temperature control study discussed 
later in this report, the constant-volume flow rate connector was replaced by a pump connector along with a user-supplied, pressure-drop-versus-flow-rate pump curve.

A heat exchanger macro (represented by the long oval with the black dot) can be seen near the top of the diagram in Figure 3. This heat exchanger macro is shown in Figure 5 and is labeled ' $\mathrm{hx}$ macro 2' within the SINDA/FLUINT model. A heat exchanger macro is not a submodel; rather it provides a convenient means of generating a series of junctions, paths, and heat transfer ties to form a heat exchanger.

Also seen in Figure 3 are connections to thermal submodels (represented by the diamonds). Connections are made from the junction nodes to the thermal submodels with heat transfer ties. The thermal submodels and heat transfer ties to them will be discussed in the following section.

In the primary flow loop (Figure 3), the pump supplies a manifold which provides water to each of the four segments. Within a segment, the flow is divided equally into upper and lower branches (see Figure 6). The upper and lower branches signify the upward- and downwardoriented plates, respectively. (Note that the water in each segment flows in opposite directions to promote temperature uniformity within the structure.) The flow is then further divided between the cavity manifold and the coupling cell manifold with a ratio of approximately 10:1-the majority flowing to the cavities. This ratio was set prior to the initiation of the modeling effort based on the assumption that heat dissipation in the coupling cells would be minor compared with the cavities. After flowing through each of the segments, the water is then collected in a return manifold and routed through the heat exchanger. The water returns to the pump following the heat exchanger.

Incorporation of CFD Results. Geometric details of the flow manifolds and cooling channels within the segments were known prior to the start of this modeling effort (Figure 2). The coupling cell hydraulic diameter and length were modeled based on the actual dimensions. The pressure drop across the coupling cell cooling channel was calculated by SINDA/FLUINT based on these dimensions. The 4-channel/1-channel pairs alternate along the length of a segment, as shown in Figure 7. A CFD modeling effort was performed on the cavity cooling passages and consisted of a set of 4- and 1-channel passages both connected to the same supply and return manifolds [3]. The results of this model provided the flow split between the 4- and 1-channel passages and the pressure drop between the supply and return manifolds. For a total flow rate of $0.153 \mathrm{~kg} / \mathrm{s}$ per cavity, the flow rate for the 4- and 1-channel passages was determined to be approximately 0.117 and $0.0366 \mathrm{~kg} / \mathrm{s}$, respectively, resulting in a ratio of 3.2:1. The resulting pressure drop between the supply and return manifolds for this flow rate was approximately 18.6 $\mathrm{kPa}$.

The results of the CFD effort were incorporated into the SINDA/FLUINT model. The 4-channel passages were modeled as four, equally sized channels, and the branching 1-channel passage was modeled as a single channel. The hydraulic diameter and line lengths of these channels were modified slightly by trial and error to obtain nearly equivalent pressure drop for the flow rate within the CFD model. The modified channel geometries are shown in Table 2 compared with the actual geometries. Using these modified channel geometries within SINDA/FLUINT along 
with a flow rate per cavity of $0.153 \mathrm{~kg} / \mathrm{s}$, the resulting flow ratio between the 4 - and 1-channel passages was 3.2:1 and the resulting pressure drop was $19.4 \mathrm{kPa}$.

Table 2. Comparison of Actual and SINDA/FLUINT Channel Geometries.

\begin{tabular}{|l|c|c|}
\hline \multicolumn{1}{|c|}{ Parameter } & Actual Geometry & Modified Geometry \\
\hline 4-Channel hydraulic diameter & $3.16 \mathrm{~mm}$ & $3.55 \mathrm{~mm}$ \\
\hline 4-Channel length & $0.5 \mathrm{~m}$ to $0.68 \mathrm{~m}$ & $0.5 \mathrm{~m}$ \\
\hline 1-Channel hydraulic diameter & $3.16 \mathrm{~mm}$ (upper), $4.29 \mathrm{~mm}$ (lower) & $4.00 \mathrm{~mm}$ \\
\hline 1-Channel length & $0.2 \mathrm{~m}$ (upper), $0.6 \mathrm{~m}$ (lower) & $0.6 \mathrm{~m}$ \\
\hline
\end{tabular}

Even though the 4-channel passages were modeled as four, separate channels (as shown in Figure 7), they appear in the SINDA/FLUINT diagram (Figure 6) as only one path. This is because SINDA/FLUINT has an option called duplication factors which provides the user with the ability to numerically duplicate identical paths, as opposed to creating multiple paths between two junctions. For the 4-channel paths, both the upstream and downstream duplication factors were set to a value of 4 . In essence, these factors indicate that four times the flow of one tube is leaving the upstream junction and entering the downstream junction.

Pipe Lengths, Valves, Elbows, and Tees. Pipe lengths for this model were estimated based largely on those for the existing Low Energy Demonstration Accelerator (LEDA) hot model at Los Alamos. Loss factors for ball valves in the fully open position were derived from manufacturer's specifications [4]. Plumbing fittings such as elbows and tees were distributed within the model at obvious turning and branching locations. Loss factors for elbows and tees were obtained from [5]. Additional elbows were added, as a safety margin, to account for possible turning locations not anticipated in this model. Pipe lengths and the location of elbows and tees are shown in Figures 8 and 9 for the primary loop and for a segment, respectively. The loss factors for the open ball valves and pipe fittings are shown in Table 3. For conservatism, the loss factor for all fully open valves was set to 0.4 .

Table 3. Loss Factors for Valves, Elbows, and Tees [4, 5].

\begin{tabular}{|l|c|}
\hline \multicolumn{1}{|c|}{ Fitting Type } & Loss Factor $=\Delta \mathbf{p} /\left(\mathbf{0 . 5} \rho \mathbf{V}^{\mathbf{2}}\right)$ \\
\hline 2" Valve Size & 0.27 \\
\hline 1 1/2" Valve Size & 0.22 \\
\hline 1" Valve Size & 0.33 \\
\hline 3/4" Valve Size & 0.34 \\
\hline 1/2" Valve Size & 0.45 \\
\hline Flanged 90 Elbow & 0.3 \\
\hline Flanged Tee, Line Flow & 0.2 \\
\hline Flanged Tee, Branch Flow & 1.0 \\
\hline
\end{tabular}




\section{Thermal Submodels}

Five thermal submodels were included in the baseline SINDA/FLUINT model. The heat exchanger between the primary and secondary cooling loops and each of the hot model segments are represented by a thermal submodel. The diagram for the 'maint' heat exchanger is shown in Figure 10. Diagrams for partial-segment 347 ('ps347') and segment 347 ('s347') are shown in Figures 11 and 12, respectively. Diagrams for partial-segment 183 ('ps172') and segment 183 ('s172') are shown in Figures 13 and 14, respectively. (Hot model segment 183 was initially designated as segment 172, therefore, the SINDA/FLUINT naming convention reflects this earlier designation.)

Within thermal submodel diagrams, the oval symbols represent arithmetic nodes and the square symbols represent diffusion nodes. These nodes are connected together with conductors (labeled with 'L's). Arithmetic nodes have zero capacitance (energy into these nodes must always equal the energy out) and diffusion nodes have thermal capacitance. The connectors in these submodels are linear conductors meaning that the rate of energy transport through them is proportional to the temperature difference across them. The diamond symbols in the thermal submodel diagrams represent connections to fluid submodels. Connections between thermal and fluid submodels are made with heat transfer ties (labeled with 'T's).

All of the ties used in this model were 'HTNS' ties. With an HTNS tie, SINDA/FLUINT calculates the heat transfer coefficient based on the diameter, length, and flow velocity within a user-selected path. The node within the thermal submodel represents the average wall temperature and the upstream and downstream junctions represent the fluid temperatures. The user also has the option of incorporating a path fraction that acts as a multiplier on heat transfer (can represent either an area or heat transfer coefficient multiplier). Since the cooling channels within the segments were modeled realistically, the default path fraction of 1.0 was used for all cooling channel paths within segments. Ties were attached between each cooling channel and the copper plate with which the cooling channel made contact (see Figure 11). On average, each plate was connected with heat transfer ties to three cooling channel paths. For the ties within the heat exchanger, path fractions were modified to simulate the operation of a vendor-supplied heat exchanger. The heat exchanger design and modeling will be discussed further in Section 4.0.

To edit a thermal submodel, choose 'thermal submodels' from the model 'control panel,' and double-click on submodel name of interest. A submodel 'control panel' will appear. From this panel, select 'edit network.' The only option used on the thermal submodel 'control panel' was the 'source' option. This option allows heat sources to be entered for nodes within a thermal submodel. A source was applied to all of the copper plates within each of the segment thermal submodels to simulate the RF power dissipated in the structure. An example of the information entered into the 'source' panel for partial segment 347 is shown below:

1, heat

2, heat

3, heat

4, heat

5, heat 
In this example, the leading integer is the number of the node to which the source is applied. The variable 'heat' is a spreadsheet register (discussed subsequently) which contains the value of the source (for the present example, the units on heat input are Watts).

\section{Spreadsheet Registers}

Spreadsheet registers are user-defined variables that can be used almost anywhere within the input file that values are required. Use of registers enables variables to be used for key parameters such as pipe diameters so that parametric trade studies can easily be performed. In addition, registers are used as design variables for goal seeking and optimization. The registers used for this model can be found in Appendix A along with a brief description of each. 


\section{RUNNING SINDA/FLUINT}

This section describes the operation of SINDA/FLUINT. The initial setup and execution of the model is discussed including the use of a single-phase water database. Also discussed is running the model with, and without, thermal submodels included. Use of the solver to determine valve settings will be covered along with running multiple cases to parametrically vary line diameter.

\section{Initial Setup and Execution}

Options Data. First from the model control panel, choose 'options data.' In this pop-up window, the only inputs used for the present modeling were 'title,' 'model,' 'output,' and 'save.' Choose a title (e.g. SNS Hot Model), let 'model' default to 'ROOT,' and provide output and save filenames with extensions '.out' and '.sav,' respectively. The output file is ascii output from a given run and the save file is the binary output from the run, which is subsequently read in by SinapsPlus.

Operations. Next from the model control panel, choose 'operations.' In this pop-up window, you will be entering both SINDA/FLUINT and FORTRAN commands. The following example illustrates the text found in 'operations' for simple, steady-state operation of the hot model:

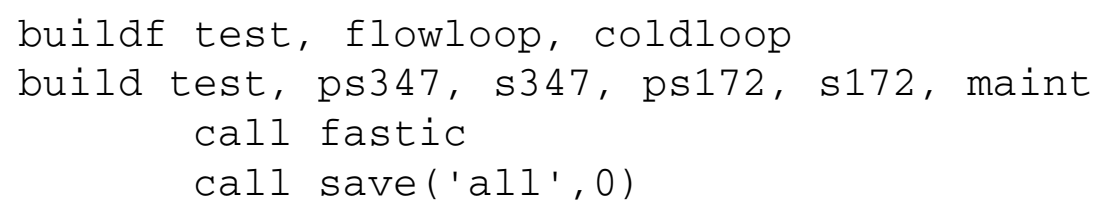

The submodels must be 'built' prior to executing the run, which is accomplished in the first two lines. The fluid submodels are built first with the 'buildf' command followed by the thermal submodels with the 'build' command. The word 'test' following the command can be any word and does not affect the operation of the code. Following the comma after 'test,' the names of the submodels must appear. After building the submodels, there are two FORTRAN subroutine calls. The first is a call to 'fastic' which operates SINDA/FLUINT in a steady-state mode to achieve a solution. The next is a call to 'save', which generates the 'sav' file. The FORTRAN calls must be indented properly (to the $7^{\text {th }}$ column). Within this window, use of the 'tab' for indenting the FORTRAN lines is acceptable.

Global Control Data. Next, from the model control panel, choose 'global control data.' In this pop-up window, you will be entering global, thermal, and fluid control parameters. What follows is a description of the inputs used for the present modeling effort. On the 'global' tab sheet, the 'SI' units box was checked and absolute zero was set with the 'abszro' parameter to -273.15 . This setting for absolute zero caused all temperature units in the program to be interpreted in ${ }^{\circ} \mathrm{C}$. In addition, the atmospheric pressure was set to $78,000 \mathrm{~Pa}$ (approximately a standard day at Los Alamos). Finally, the max number of iterations was set to 1000 using the 'nloops' parameter. On the 'thermal' tab sheet, 'ebalsa' was set to 0.0001 to force a tighter convergence tolerance on thermal energy balance. On the 'fluid' tab sheet, 'rebalf' was varied between 0.01 and 0.0001 as needed to vary convergence tolerance on fluid energy balance. 
Fluid Property Data. ('Global user data' and 'subroutines' were not used.) Next, from the model control panel, choose 'fluid property data' and select the 'includes' option. In this pop-up window, the user can input an alternate fluid property database. For the present modeling effort, a single-phase water database was used. Since the SNS hot model will only operate in a singlephase mode, the single-phase database was used to speed model convergence and avoid model instabilities. These model instabilities can be caused by excursions into the two-phase regime during the iterative solution process. This single-phase water data base was included in the 'includes' pop-up window with the following command:

include fld9718.txt

The file 'fld9718.txt' must reside in the user's working directory. This file is shown in Appendix B. The properties in this file are given in English units, however, the current model is set to SI units. SINDA/FLUINT correctly interprets and converts the units for the user so that this database can be used regardless of the choice of units selected. Also, the fluid ID number for each fluid submodel should be set to '9718.' To do this, open the 'fluid network' window for each of the fluid submodels, select the 'Create/Edit' pull-down menu, choose 'header,' then 'set fluid ID' and enter '9718' into this window.

Registers. ('Mixture data' was not used.) Next, from the model control panel, choose 'registers.' This opens a 'spreadsheet' in which you can enter variables to be used as input for your model. The registers for the current model can be found in Appendix A.

Thermal and Fluid Submodels. The next two options on the 'control panel' pop-up either thermal or fluid submodel browsers. Use these browsers to add, delete, or show submodels. For the current effort, five thermal submodels were used ('maint,' 'ps347,' 's347,' 'ps172,' and 's172') and two fluid submodels were used ('flowloop' and 'coldloop').

Utilities. The 'utilities' option can be used to write a SINDA/FLUINT input file. This can be useful to examine what explicit commands are being written to this file based on SinapsPlus' interpretation of inputs. The 'utilities' option can also be used to create an archive of the SINDA/FLUINT model. The archived model contains everything within SinapsPlus, including the diagrammed representations of the submodel networks. This model can then be transferred to another computer or emailed to Cullimore and Ring so that they can debug problems. Any external 'include' files (such as the single-phase water database), however, are not included in the archive and must be transferred separately.

Save Everything. This option on the 'control panel' saves the entire model to disk. The model can be changed and executed many times without saving to disk, however, if SinapsPlus is exited prior to saving the changes, they will be lost. This command is identical with the 'save everything' on the 'launcher' panel.

The Solver. 'The solver' option pops-up a list of menus that require inputs for use in goalseeking. This option and its use will be discussed in greater detail in Section 4. 
Run SINDA/FLUINT. With this option, SINDA/FLUINT can be run either to compile only (to check out the model) or to compile and run. This option automatically transfers control to SINDA/FLUINT from SinapsPlus and, when finished, transfers control back to SinapsPlus.

Exit Model. This option exits the current model and transfers control back to the 'launcher.'

\section{Running Without Thermal Submodels}

There are instances when it is convenient to run without the thermal submodels (e.g. when optimizing valve settings). To do this, select 'operations' from the model 'control panel' and move the thermal submodel 'build' command to the end of the entry as follows:

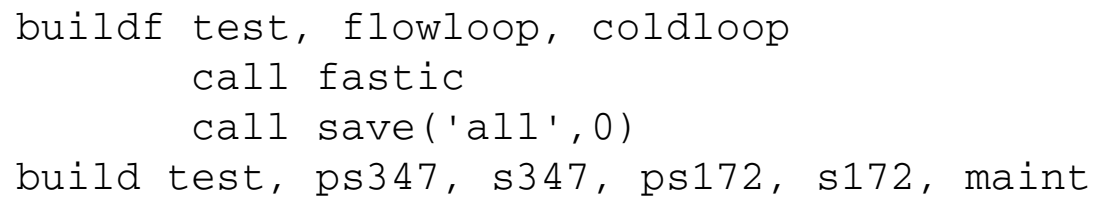

Because the thermal submodels are included in the SINDA/FLUINT model, they must be 'built' or an error will occur. If they are 'built' after the call to 'fastic,' however, they will not be included in the solution of the model.

\section{Using the Solver to Determine Valve Settings}

For this study, the 'solver' option was used to determine valve settings in the 'flowloop' fluid submodel, as opposed to the laborious trial-and-error approach. From the main manifold of the flow loop, a separate valve controls the flow rate to each of the four segments. From this manifold, flow is divided based on the power dissipation in a segment. The two partial segments dissipate $5 \mathrm{~kW}$ each and the two full segments dissipate $20 \mathrm{~kW}$ each. The flow distribution, therefore, is approximately $6.5 \mathrm{gpm}$ to each partial segment and $26 \mathrm{gpm}$ to each full segment for a total of $65 \mathrm{gpm}$. Once inside a segment, the flow divides again between the upward- and downward-oriented plates. The flow split at this junction is assumed to be 1:1. Following this flow split, the flow divides one more time between the cavities and coupling cells. At this junction, the flow split is assumed to be 10:1 in favor of the cavities. The valve settings had to be determined from the innermost to the outermost flow split. If the order were reversed, a change to an inner valve setting would vary the flow resistance seen by any upstream valves, thus affecting the flow rate through them.

The use of the solver will be discussed employing the diagram of segment 347 shown in Figure 15. Starting with one of the innermost branches with valves labeled ' 221 ' and ' 222 ', the desired flow split is 10 parts through valve '222' and 1 part through valve '221.' Since most of the flow will be passing through valve '222,' it is reasonable to expect that this valve will be fully open. In the 'spreadsheet registers,' therefore, set the k-factor for this valve (ks3hm) to 0.4 (see Table $3)$.

The first step in using the 'solver' is to modify the logic in the 'operations' panel as follows:

buildf test, flowloop, coldloop

c call fastic 


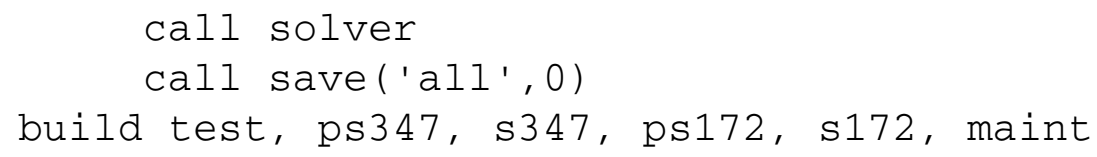

The call to 'fastic' is commented out and the call to 'solver' is entered in its place. In addition, the thermal 'build' statement is moved to the end of the logic block to deactivate the thermal 
submodels while the valve settings are being set. This saves considerable time for the multiple iterations of the 'solver.'

Next, select 'solver data' from the 'solver' option on the 'control panel.' 'Object' is the value of the objective. In this case, the object will be the ratio of the flow through valve '222' to the flow through valve '221.' There is no need to set a value for this parameter in this panel ('object' will be made into an output variable in a subsequent panel). 'Goal' is the target value of the 'object.' Since a flow split of 10:1 is desired, the value entered for 'goal' is 10.

Next, choose 'design data' from the 'solver' option on the 'control panel.' The design variable (the variable that will change to achieve the objective) is the k-factor for valve ' 221 ' ('ks3hu'). In the 'design data' panel, therefore, set the variable name to 'ks3hu.' Then set the minimum and maximum values of this variable to a range which is believed to include the solution, say 0.1 and 20.

Next, select 'solver procedure' from the 'solver' option on the 'control panel.' The solver logic for this goal-seeking operation is entered in this panel as follows:

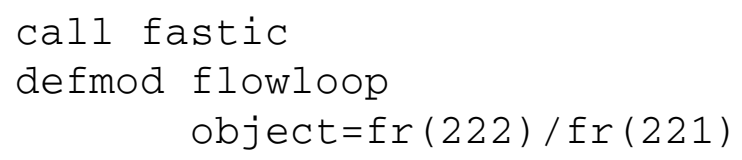

The call to 'fastic' is used since a steady-state solution procedure is desired. The next line sets the default module as 'flowloop' (the primary cooling loop). It is from this module that the variables in the following line are obtained. Once the 'fastic' solution is complete, the final line sets 'object' to the ratio of the flow through path (valve, in this case) '222' to the flow through path '221'. The solver will compare the value of 'object' against the 'goal' value, adjust the design variable appropriately, and then repeat this logic block.

At this point, run SINDA/FLUINT. The output from the solver will appear in the ascii '.out' file. For this particular case, the solver found that to achieve a flow split of 10:1, the k-factor for valve '221' (ks3hu) should be set to 4.65. This 'solver' solution process is repeated for each of the innermost valve pairs, then for the intermediate level valve pairs, and finally for the valves to each of the segments from the main manifold. The final valve settings for this effort can be seen in the 'spreadsheet registers' found in Appendix A.

\section{Running Multiple Cases to Parametrically Vary Pipe Diameter}

Using 'spreadsheet registers,' parametric studies can easily be performed. A study was conducted to determine appropriate pipe diameters for the hot model flow loop. This was accomplished by modifying the 'operations' logic block as follows:

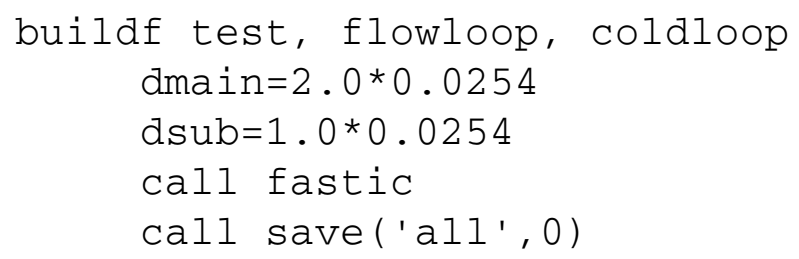




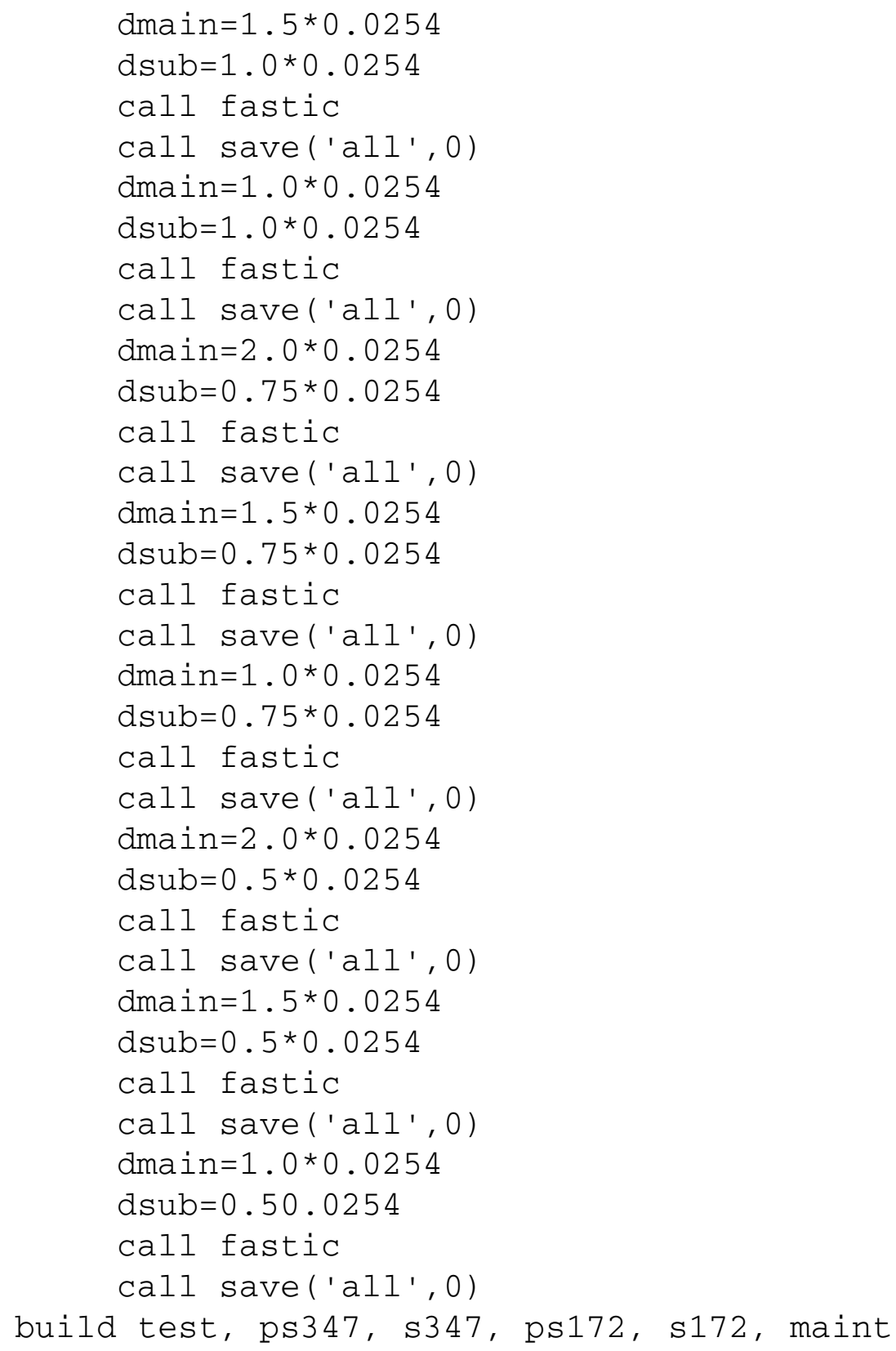

Values of the diameter for the main and secondary pipe sizes are set within this logic block (these must also be defined as registers in the 'spreadsheet'). Next, 'fastic' is called to run a steady-state solution followed by a call to 'save' to save the data for viewing within SinapsPlus. This operation is repeated until all of the desired permutations have been completed. Again, the thermal 'build' state has been placed at the bottom of the logic block to deactivate the thermal submodels during this parametric study. 


\section{MODELING RESULTS}

In this section, the modeling results are presented for the various design and analysis studies that have been performed. These studies included sizing of the pipe diameters, heat exchanger, and pump. Also, the results from the temperature control trade study will be presented. In addition, the study of manifold cross-flow due to the location of the RF window will be discussed.

\section{Pipe Sizing}

A study was conducted to determine appropriate pipe diameters for the hot model flow loop. This study is a result of the conflicting needs to reduce diameter, which lowers cost, and to increase diameter, which minimizes pressure drop. The diameters of two different sections of pipe were investigated parametrically. The first section investigated was pipe in the major portion of the cooling loop that includes the supply and return manifolds for flow to/from the four segments. The pipe diameters chosen for this first section of pipe were $2,1 \frac{1 / 2}{2}$, and 1 ". The second section investigated was the minor section of pipe connecting the four segments to the main supply and return manifolds. The pipe diameters chosen for this second section of pipe were $1,3 / 4$, and $1 / 2 ”$.

The logic used in the 'operations' panel to conduct this trade study is listed in Section 3.0. Data were generated for all permutations of the six different pipe diameters for a total of nine runs. For each permutation, pressure drop within the flow loop was calculated. These values of pressure drop are plotted in Figure 16 against major pipe diameter for varying values of minor pipe diameter.

From Figure 16, it can be seen that the 'knee' in the curve of pressure drop versus major pipe diameter occurs at a diameter of $1 \frac{112}{2}$ ". Reducing the diameter below $1 \frac{1 / 2}{2}$ " generates a large increase in pressure drop. Increasing the diameter above $1 \frac{112}{2}$, however, results in only minor pressure drop savings. A diameter of $1 \frac{1 / 2}{2}$, therefore, was selected for the major pipe diameter. The 'knee' in the curve for minor pipe diameter occurs at a diameter of $3 / 4$ ". Since the minor pipe directly feeds the 1"-diameter manifolds internal to the segments, however, a minor pipe diameter of 1 " was selected.

\section{Heat Exchanger Modeling}

A study was conducted to determine the appropriate heat exchanger size for the hot model flow loop. A flat plate heat exchanger was selected due to its high efficiency and compact dimensions. This type of heat exchanger has high efficiency because its ribbed channels promote turbulent flow and the plate packaging provides large surface areas for heat transfer. This high efficiency, however, results in increased pressure drop. Several temperature and flow rate combinations were chosen to simulate operating conditions for the SNS hot model. These operating conditions were sent to a heat exchanger manufacturer to determine the optimum heat exchanger size. As a result of this sizing effort, a FlatPlate ${ }^{\circledR}$ model FP10x20-60 was selected. This heat exchanger has approximately 30 flow channels resulting in a nominal, heat transfer surface area of $7.07 \mathrm{~m}^{2}$.

A heat exchanger macro within SINDA/FLUINT was used to simulate one channel of the 30channel (in parallel), flat plate heat exchanger (see Figures 5 and 10). Duplication factors on the upstream and downstream paths connecting the heat exchanger to the primary flow loop were 
used to simulate the entire 30-channel heat exchanger. Duplication factors allow the user to model multiple identical paths using only a single path in SINDA/FLUINT. On the upstream node, the upstream duplication factor, 'DUPI,' was set to 30 and the downstream factor, 'DUPJ,' was set to 1 . On the downstream node, 'DUPI' was set to 1 and 'DUPJ' was set to 30. In effect, the heat exchanger was modeled with only one path, however, the duplication factors simulated 30 times the mass flow of this single channel. The diameter of the channel was set to $1 \mathrm{~cm}$ to match approximately the internal velocity within the heat exchanger. The length of the channel was set to $7.5 \mathrm{~m}$ to match the heat transfer surface area.

SINDA/FLUINT uses both laminar and turbulent heat transfer correlations to determine internal heat transfer coefficients for the heat exchanger channels. The ribbed geometry of the channels, however, provides an additional heat transfer enhancement and lower the laminar-to-turbulent transition Reynolds number. SINDA/FLUINT provides a heat transfer multiplier variable, 'pfract,' that enables the user to boost heat transfer in a path. Based on the heat exchanger manufacturer's heat transfer coefficients, 'pfract' was set to a value of 12 on both the hot and cold sides of the heat exchanger. To match the pressure drop within the heat exchanger, SINDA/FLUINT permits the user to set a loss factor for the tubing. Loss factors of 12.3 and 7.0 were set for the flow in the hot side and cold side, respectively.

This model of the heat exchanger provides accurate pressure drop as a function of flow rate, which now enables pump sizing. This model also provides accurate heat transfer coefficients for most of the design operating range. Part of this range, however, is not accurate due to the differences in the laminar-to-turbulent transition Reynolds number between the SINDA/FLUINT model and the actual heat exchanger. The SINDA/FLUINT heat exchanger model begins to lose accuracy when the heat exchanger flow rate drops below $10 \mathrm{gpm}$.

\section{Pump Sizing}

Once all of the known losses have been programmed into the SINDA/FLUINT model, the pump size can be determined. As mentioned previously, there were some unknown losses, such as those for the filter and expansion tank. In addition, a pressure loss safety margin was needed to account for unanticipated losses. A loss factor of 10 (within a $11 / 2$ "-diameter pipe) was chosen to represent these unknown losses and the loss safety margin. The pump was sized at the design flow rate of $65 \mathrm{gpm}$. The total pressure drop within the primary flow loop at this flow rate was approximately $35.8 \mathrm{psi}(247 \mathrm{kPa})$. A schematic of the flow loop is shown in Figure 17 with pressures at various locations shown.

\section{Temperature Control Trade Study}

A study was performed to aid in the selection and development of a primary loop, temperaturecontrol methodology. Three different methodologies were selected to control temperature of water entering the RF structure. First, vary cold-side heat exchanger (chiller water) flow rate. Second, vary hot-side heat exchanger flow rate (using a bypass loop) while maintaining constant flow rate to the RF structure. And third, vary hot-side heat exchanger flow rate while allowing variable flow rate to the RF structure. A schematic of the overall flow loop is shown in Figure 17. 
With the first method, hot-side temperature is controlled by varying water flow rate on the cold side of the heat exchanger. The change in flow rate on the cold side results in both a change in cold side heat transfer coefficient (heat exchanger efficiency), and a change in the heat capacity of the cooling water. This method appeared to be the most logical and straight-forward approach for the hot model application for two reasons. First, the cold-side flow rate could be varied rapidly with the use of a bypass valve in the cold flow loop. This rapid variation in flow rate would result in a relatively low time constant for varying hot side temperature. Secondly, the flow rate in the primary loop could remain constant. This would result in a variable RF inlet temperature but a constant temperature rise of the cooling water through the RF structure.

The results of hot-side temperature control for the first method are shown in Figure 18. Figure 18 shows a plot of hot-side, heat exchanger outlet temperature (inlet temperature for the RF structure) versus cold-side water flow rate. The four data points shown on this plot were obtained from the heat exchanger manufacturer for hot model design conditions (SINDA/FLUINT was not used to generate these data). The hot-side data span the required operating range of $\pm 7.5^{\circ} \mathrm{C}$ about the mean operating temperature of $24.9^{\circ} \mathrm{C}$. Also shown in this figure is a curve fit of the data.

The second and third methods for controlling hot-side temperature were studied as alternatives to the first method. The advantage of these two methods is that the hot-side temperature control is not coupled to the flow rate or temperature of the cooling water on the cold side, provided they are constant. This de-coupling of the hot side from the cold side is attractive for the actual SNS linac application. In the second method, hot-side temperature is increased by bypassing some flow around the heat exchanger (a heat exchanger bypass path was added to the SINDA/FLUINT model to perform this study). A reduction in hot-side heat exchanger flow results in a corresponding reduction in heat transfer coefficient. Since heat transfer has become less efficient in the heat exchanger, the hot side temperature must increase to force the same amount of heat through the heat exchanger.

As flow is bypassed, the overall flow resistance in the primary loop decreases. For the second control method, flow is held constant in the primary loop with the use of a constant-flow regulating valve (shown in Figure 17). The third method is similar to the second method except that the constant-flow regulating valve is not used. With the third method, flow rate is permitted to change as the flow resistance in the primary loop changes. To simulate the third control method with SINDA/FLUINT, the constant-flow 'connector' was replaced by a 'pump' connector. In addition, an actual pump curve was entered into the model to reflect the change in pump flow rate for a change in flow resistance. This pump curve was entered into the 'array data' panel of the 'flowloop' submodel 'control panel' as follows:

$\begin{array}{ll}0.0, & 32.39, \\ 0.000631, & 32.33, \\ 0.001262, & 32.02, \\ 0.001893, & 31.24, \\ 0.002524, & 30.03, \\ 0.003155, & 28.39, \\ 0.003786, & 26.33,\end{array}$


$0.004417,23.85$,

$0.005048,20.95$, 


$$
\begin{array}{ll}
0.005679, & 17.62, \\
0.00631, & 13.86, \\
0.006941, & 9.68
\end{array}
$$

where the array is numbered ' 1 ,' the first column of numbers is volume flow rate in units of $\mathrm{m}^{3} / \mathrm{s}$, and the second column is pump pressure head in units of meters.

The SINDA/FLUINT model was used to determine pressure drops for the study of these two methods. Because the heat transfer component of the SINDA/FLUINT heat exchanger model was inaccurate for some design conditions (due to the inaccuracies in the SINDA/FLUINT heat exchanger model below a heat exchanger flow rate of approximately $10 \mathrm{gpm}$ ), an Excel spreadsheet model was developed. This spreadsheet model was used to conduct the heat transfer portion of this temperature control study. The primary component of the Excel spreadsheet model was the heat transfer coefficient within the heat exchanger. To obtain a correlation for the heat transfer coefficient, a regression analysis was performed with the heat exchanger manufacturer's data. From this analysis, a correlation for hot-side heat transfer coefficient versus hot-side water flow rate and temperature was generated as follows:

$$
\mathrm{HTC}\left[\mathrm{W} /\left(\mathrm{m}^{2 \circ} \mathrm{C}\right)\right]=164.9 * \mathrm{FR}_{\mathrm{HX}}[\mathrm{gpm}]+95.7 * \mathrm{~T}_{\text {Mean, } \mathrm{HX}}\left[{ }^{\circ} \mathrm{C}\right]
$$

where HTC is hot-side heat transfer coefficient, $\mathrm{FR}_{\mathrm{HX}}$ is hot-side flow rate, and $\mathrm{T}_{\text {Mean, } \mathrm{HX}}$ is the mean water temperature on the hot side. This correlation was used in a spreadsheet model along with the Excel 'solver' option to calculate mixed temperatures in the primary loop as a function of the amount of flow bypassing the heat exchanger. For a given heat exchanger bypass flow, the 'solver' option in Excel was used to vary heat exchanger inlet temperature until the correct heat transfer rate was achieved. The heat exchanger inlet temperature affects both HTC ( $\mathrm{T}_{\text {Mean, HX) }}$ and the log-mean temperature difference which are both used in the calculation of heat transfer rate.

The hot-side temperature control results for the second method (variation of hot-side flow rate while maintaining constant flow rate to the RF structure) are shown in Figures 19 and 20. Figure 19 shows a plot of mixed temperature (at the mixing location prior to the pump) versus hot-side heat exchanger flow rate. The three curves shown on this plot are for three different cold-side inlet temperatures and flow rates. For the lowest, cold-side inlet temperature $\left(5^{\circ} \mathrm{C}\right)$, the magnitude of the slope of the curve is relatively high. This large slope could be problematic for a temperature control algorithm because a slight change in flow rate results in a large change in mixed temperature. The curve for the cold-side flow rate of $15^{\circ} \mathrm{C}$ appears to have a more accommodating slope. Figure 20 shows a plot of pressure drop versus hot-side flow rate. One curve shows the pressure drop through the bypass valve and the other shows the pressure drop through the constant-flow valve.

The hot-side temperature control results for the third method (variation of hot-side flow rate while permitting variable flow rate to the RF structure) are shown in Figures 21 and 22. Figure 21 shows a plot of mixed temperature (at the mixing location shown in Figure 17) versus hotside heat exchanger flow rate. The data in this plot are very similar to those for the $15^{\circ} \mathrm{C}$ inlet 
temperature curve in Figure 19. The pressure drop through the bypass valve for this case is also vary similar to the data in Figure 20. The reason for the similarity in the results for the second 
and third control methods can be found in Figure 22. This figure shows a plot of total flow rate through the pump versus hot-side, heat exchanger bypass flow. As flow is bypassed around the heat exchanger, the overall flow resistance within the loop decreases, therefore, the pump flow rate increases. This flow rate increase, however, is minor (approximately $6 \mathrm{gpm}$ ).

The results of this control methodology study indicate that varying cold-side flow rate is an excellent approach for controlling hot-side temperature. If it is desired, however, to control hotside temperature without varying either cold-side flow rate or temperature, then either the second or third control method could be used successfully. The advantage of the second method is that hot side flow rate, and thus water temperature rise through the RF structure, remains constant. The advantage the third method is the elimination of the constant-flow valve. The hot-side flow rate for the third method, however, could vary by as much as $10 \%$.

\section{Study of Cross-Flow Due to RF Window Location}

A study was performed to investigate the impact of cross-coupling segment 183's internal flow manifolds due to the penetration into the structure of the RF window. In this case, the RF window is planned to penetrate the structure between the $5^{\text {th }}$ and $6^{\text {th }}$ plates (out of 20 plates). The proposed change in channel flow for this penetration is shown in Figure 23. This change would create a cross-coupling between the pairs of supply and return manifolds that run the length of the segment. The goal of this study was to determine if this cross-coupling had any adverse affects on the flows within these pairs of manifolds.

Figure 24 shows the SINDA/FLUINT representation of the cross-coupled manifolds. Table 4 shows the pressure drop and flow rate results for the uncrossed and crossed channel.

Table 4. Comparison of Uncrossed and Crossed Channel.

\begin{tabular}{|l|c|c|}
\hline \multicolumn{1}{|c|}{ Parameter } & Uncrossed Channel & Crossed Channel \\
\hline Flow rate $(\mathrm{kg} / \mathrm{s})$ & 0.03402 & 0.03367 \\
\hline Pressure drop $(\mathrm{kPa})$ & 16.9 & 16.6 \\
\hline
\end{tabular}

The results of this study show a negligible impact on the flow and pressure drop of the system due to cross-coupling of manifolds at the RF window location.

\section{Transient Study to Determine Temperature Change vs. Time}

A study was performed to investigate the transient response time for changes in primary cooling water temperature. The transient option was used within SINDA/FLUINT to perform this study. The code entered in the 'operations' panel of the 'hotmodel control panel' was as follows:

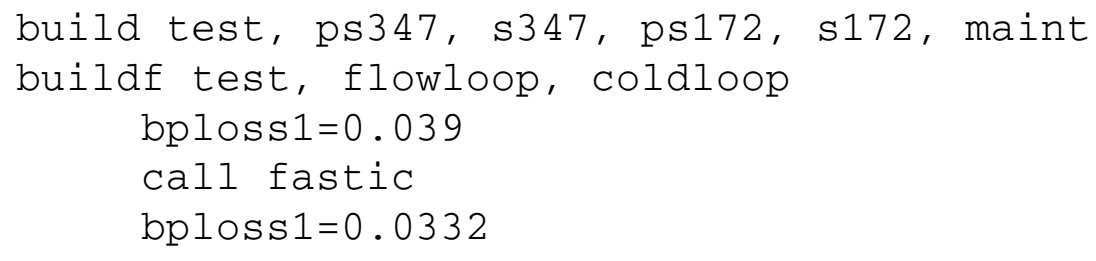


call fwdbck 
where the initial condition is set up by setting the bypass valve to a loss coefficient of 0.039 and then calling 'fastic' (the steady-state solver). Next, the bypass valve setting is modified to 0.0332 and a call to 'fwdbck' (the transient solver) is made. Within the 'global control data' panel of the 'hotmodel control panel,' the end time of the transient, 'timend,' is set to '(flowloop.t112 > 26.45) ? timen : 1.0e30' which compares the temperature of node 12 within the 'flowloop' submodel to a value $\left(26.45^{\circ} \mathrm{C}\right)$. If the node temperature is greater than this value, 'timend' is set to 'timen' (the current time) and the transient solution stops. If the temperature of node 12 is less than the value, 'timend' is set to a large number so that the transient solution will continue. (The comparison value of $26.45^{\circ} \mathrm{C}$ was determined prior to running the transient using a steady-state solution with the valve setting of 'bploss $1=0.0332$.') Within the 'thermal' tab of this same panel, the print interval was set to 'output $=10,000$ ' to negate its input and 'opeiter' was set to ' 1 ' so that SINDA/FLUINT would output at each time step. Likewise, within the 'fluid' tab of this same panel, the print interval was set to 'outptf $=10,000$ ' and 'opitrf' was set to ' 1 .'

The third temperature control method was assumed for this transient study (vary hot-side heat exchanger flow rate while allowing variable flow rate to the RF structure). Since variable flow rate is allowed, the flow to the RF structure rises above $65 \mathrm{gpm}$ (see Figure 22). The cold-side inlet temperature and flow rate were set to $10^{\circ} \mathrm{C}$ and $28.7 \mathrm{gpm}$, respectively. Two transient simulations were conducted-both from the same initial temperature (structure inlet) of $24.7^{\circ} \mathrm{C}$. The first transient examined raising the cooling water temperature by $1.8^{\circ} \mathrm{C}$ to a new steady-state temperature of $26.5^{\circ} \mathrm{C}$. The second transient raised the water temperature by $0.7^{\circ} \mathrm{C}$ to a new steady-state temperature of $25.4^{\circ} \mathrm{C}$. Results for these two simulations are shown in Figure 25 as a plot of hot model inlet temperature versus time. To raise the temperature by $1.8^{\circ} \mathrm{C}$ and $0.7^{\circ} \mathrm{C}$ with a single valve manipulation required approximately 108 and 80 minutes, respectively. For the $1.8^{\circ} \mathrm{C}$ case, the main flow rate was $70.7 \mathrm{gpm}$ and the heat exchanger bypass flow rate was $60.8 \mathrm{gpm}$. For the $0.7^{\circ} \mathrm{C}$ case, the main flow rate was $70.7 \mathrm{gpm}$ and the bypass flow rate was $60.2 \mathrm{gpm}$.

These transients were conducted by simply changing the valve setting and waiting for temperature to stabilize. The graph in Figure 25 illustrates, however, that significantly shorter response times can be achieved by manipulating the valve during the transient. For example, using the valve setting for the $1.8^{\circ} \mathrm{C}$ temperature rise results in a $0.7^{\circ} \mathrm{C}$ temperature rise in only 6 minutes. 


\section{SUMMARY}

The objective of this effort was to provide design guidance for the development of the SNS hot model. The goals of the modeling activity were to determine appropriate manifold design, line diameters, pump size, heat exchanger size, and pressure drops throughout the loop. In addition, the temperature control methodology was investigated using three different control schemes. The modeling effort employed the SINDA/FLUINT network modeling tool.

The development of a SINDA/FLUINT model was described. This model was used to simulate the CCL hot model cooling system. The general layout of the model was discussed including the separate fluid and thermal submodels, inclusion of valves and fittings, and input of CFD flow and pressure drop results for the cavity cooling channels. Some pressure drop and flow rate details within the SINDA/FLUINT model were provided by a CFD model. The operation of SINDA/FLUINT was described in detail. The initial setup and execution of the model was discussed including the use of a single-phase water database. Also discussed was running the model with, and without, thermal submodels included. Use of the solver to determine valve settings was covered along with running multiple cases to parametrically vary line diameter.

Modeling results were presented for the various design and analysis studies that were performed. These studies included sizing of the pipe diameters, heat exchanger, and pump. Also, the results from the temperature control trade study was presented. In addition, the study of manifold crossflow due to the location of the RF window was discussed. 


\section{REFERENCES}

[1] Supplied by SNS Hot Model Lead Engineer, J.D. Bernardin.

[2] SINDA/FLUINT General Purpose Thermal/Fluid Network Analyzer, Version 4.1, User's Manual, Cullimore and Ring Technologies, Inc., 1988.

[3] Performed by ESA-DE engineer, Z. Konecni.

[4] Swagelok Company Catalog, Highland Heights, Ohio.

[5] Fundamentals of Fluid Mechanics, by B.R. Munson, D.F. Young, and T.H. Okiishi, John Wiley and Sons, New York, 1990. 


\section{APPENDICES}

Appendix A. SINDA/FLUINT Spreadsheet Registers for Hot Model.

\begin{tabular}{|c|c|c|}
\hline Variable Name & Value/Expression & Description \\
\hline vflow & $65 . * 0.0000631$ & total volume flow rate in primary loop \\
\hline vflowc & 0.0018117 & volume flow rate in coolant loop \\
\hline tinit & 18.3 & initial, and plenum (source \\
\hline tcool & 10 & coolant loop temperature \\
\hline heat & 0 & source term for plates \\
\hline bploss1 & 0.1 & HX bypass loss factor \\
\hline dmain & $1.5 * 0.0254$ & main loop tube diameter \\
\hline amain & pi $^{*}$ dmain^ $2 / 4$ & main loop tube flow area \\
\hline dsub & $1 . * 0.0254$ & sub loop tube diameter \\
\hline asub & pi $^{*}$ dsub^ $2 / 4$ & sub loop tube flow area \\
\hline vhxlump & 0.001 & volume of each heat exchanger lump \\
\hline nhxh & 30 & number of hx tubes (hot side \\
\hline nhxc & 30 & number of hx tubes (cold side \\
\hline dhxh & 0.01 & heat exchanger flow passage diameter (hot side \\
\hline dhxc & 0.01 & heat exchanger flow passage diameter (cold side \\
\hline lhxh & 7.5 & heat exchanger tube length (hot side \\
\hline lhxc & 7.5 & heat exchanger tube length (cold side \\
\hline ahx & 7.07 & heat exchanger effective area \\
\hline khxh & 12.3 & k-factor for hx (hot side \\
\hline khxc & 7 & $\mathrm{k}$-factor for $\mathrm{hx}$ (cold side \\
\hline hpfract & 12 & hx hot side area multiplier \\
\hline cpfract & 12 & hx cold side area multiplier \\
\hline dlpass & 0.0254 & lower passage flow diameter \\
\hline alpass & pi*dlpass^2/4 & lower passage flow area \\
\hline dupass & 0.0094 & upper passage flow diameter \\
\hline aupass & pi*dupass $^{\wedge} 2 / 4$ & upper passage flow area \\
\hline $\mathrm{d} 4 \mathrm{ch}$ & 0.00355 & 4-channel flow diameter, per channel \\
\hline d1ch & 0.004 & 1-channel flow diameter \\
\hline duch & 0.00305 & upper-channel flow diameter \\
\hline $14 \mathrm{ch}$ & 0.5 & 4-channel flow length, average \\
\hline $11 \mathrm{ch}$ & 0.6 & 1-channel flow length \\
\hline luch & 0.6 & upper-channel flow length \\
\hline $\operatorname{gcc} 3$ & 50 & conductance between plates seg 347 (20000 \\
\hline gcc1 & 100 & conductance between plates seg 172 \\
\hline capcop3 & $8933 * 0.00472 * 385$ & rho * vol * cp of copper seg 347 (capacitance \\
\hline capcop1 & $8933 . * 0.00338 * 385$ & rho $*$ vol $*$ cp of copper seg 172 \\
\hline tplate3 & 0.081 & thickness of plates for copper seg 347 \\
\hline tplate1 & 0.039 & thickness of plates for copper seg 172 \\
\hline kelbow & 0.3 & flanged, 90-deg elbow \\
\hline kteel & 0.2 & flanged tee, line flow \\
\hline kteeb & 1 & flanged tee, branch flow \\
\hline kbypass & 50000000 & $\mathrm{k}$-factor for bypass valve \\
\hline kfilter & 10 & $\mathrm{k}$-factor for filter \\
\hline kps3 & 94.31 & $\mathrm{k}$-factor for partial segment 347 valve \\
\hline
\end{tabular}




\begin{tabular}{|c|c|c|}
\hline kps3h & 0.4 & k-factor for ps347 high valve \\
\hline $\mathrm{kps} 31$ & 119.5 & $\mathrm{k}$-factor for ps347 low valve \\
\hline kps3hu & 0.4 & k-factor for ps 347 high, upper valve \\
\hline $\mathrm{kps} 3 \mathrm{hm}$ & 39.2 & k-factor for ps347 high, main valve \\
\hline kps3lu & 101.53 & k-factor for ps347 low, upper valve \\
\hline $\mathrm{kps} 31 \mathrm{~m}$ & 0.4 & $\mathrm{k}$-factor for ps347 low, main valve \\
\hline ks3 & 0.7117 & $\mathrm{k}$-factor for segment 347 valve \\
\hline ks3h & 0.4 & k-factor for s347 high valve \\
\hline $\mathrm{ks} 31$ & 1.063 & $\mathrm{k}$-factor for s347 low valve \\
\hline $\mathrm{ks} 3 \mathrm{hu}$ & 4.65 & k-factor for s347 high, upper valve \\
\hline ks3hm & 0.4 & k-factor for s347 high, main valve \\
\hline ks3lu & 4.42 & k-factor for s347 low, upper valve \\
\hline ks31m & 0.4 & $\mathrm{k}$-factor for s347 low, main valve \\
\hline ks1 & 0.4 & $\mathrm{k}$-factor for segment 172 valve \\
\hline ks1h & 0.4 & $\mathrm{k}$-factor for s172 high valve \\
\hline ks11 & 1.028 & k-factor for s 172 low valve \\
\hline ks1hu & 5.13 & k-factor for s172 high, upper valve \\
\hline ks1hm & 0.4 & k-factor for s172 high, main valve \\
\hline ks1lu & 5.06 & k-factor for s172 low, upper valve \\
\hline $\mathrm{ks} 1 \mathrm{~lm}$ & 0.4 & $\mathrm{k}$-factor for s172 low, main valve \\
\hline kps1 & 73 & k-factor for partial segment 172 valve \\
\hline kps1h & 0.4 & k-factor for ps172 high valve \\
\hline kps11 & 124.1 & $\mathrm{k}$-factor for ps172 low valve \\
\hline kps1hu & 0.4 & k-factor for ps 172 high, upper valve \\
\hline kps1hm & 40.61 & $\mathrm{k}$-factor for ps172 high, main valve \\
\hline kps1lu & 101.49 & k-factor for ps 172 low, upper valve \\
\hline kps1lm & 0.4 & $\mathrm{k}$-factor for ps172 low, main valve \\
\hline
\end{tabular}




\section{Appendix B. Single-Phase Water Database.}

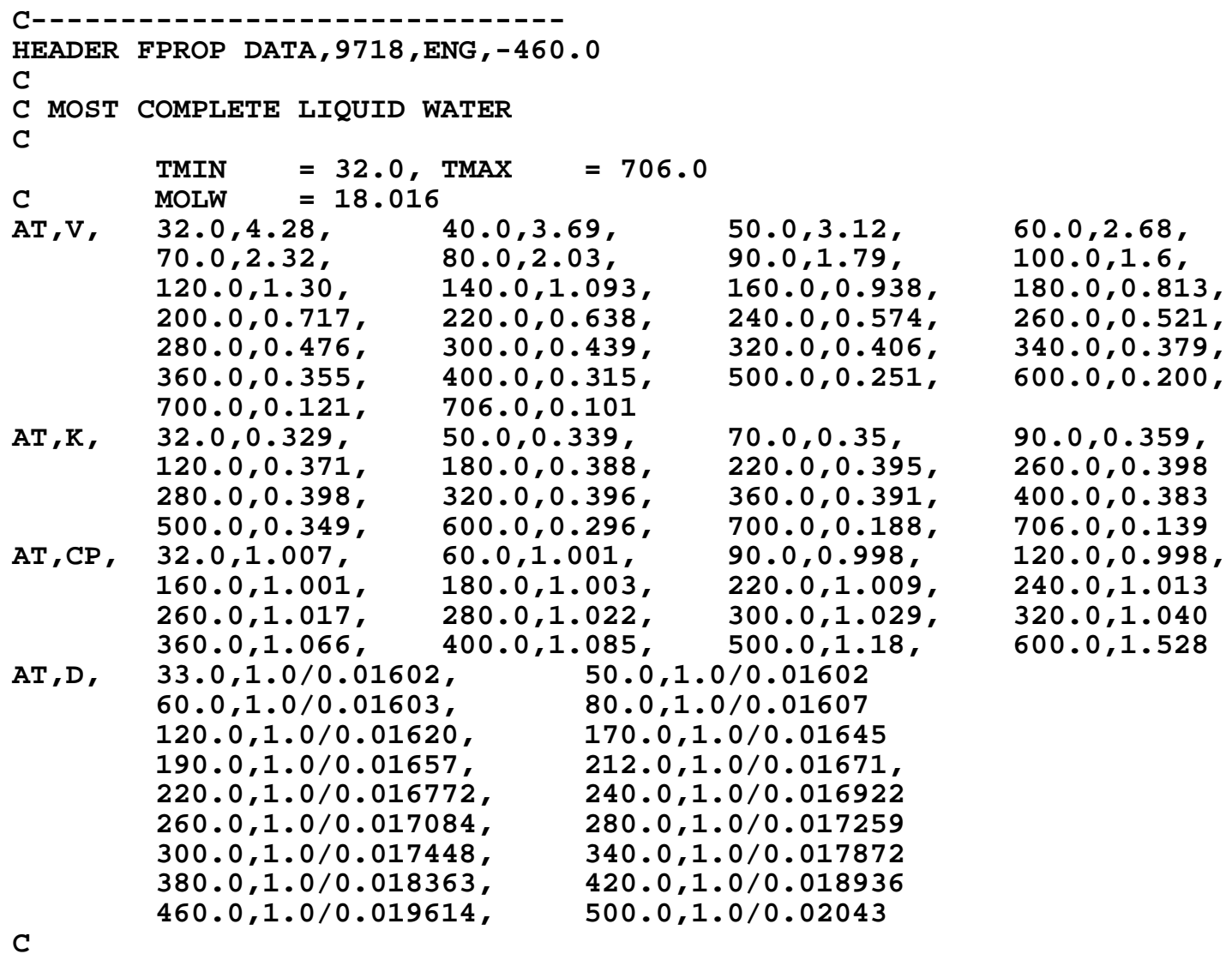




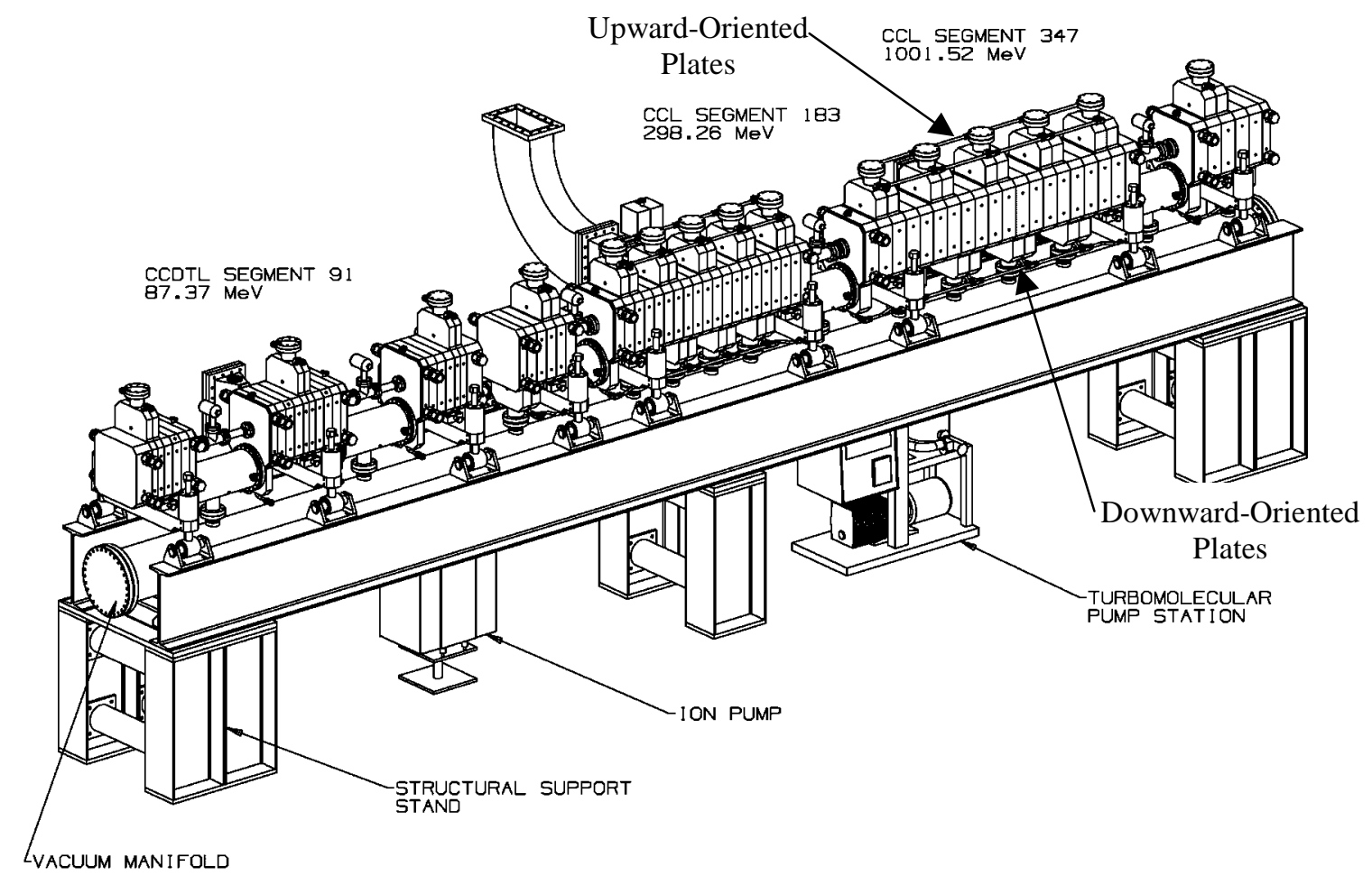

Figure 1. Drawing of SNS Hot Model.

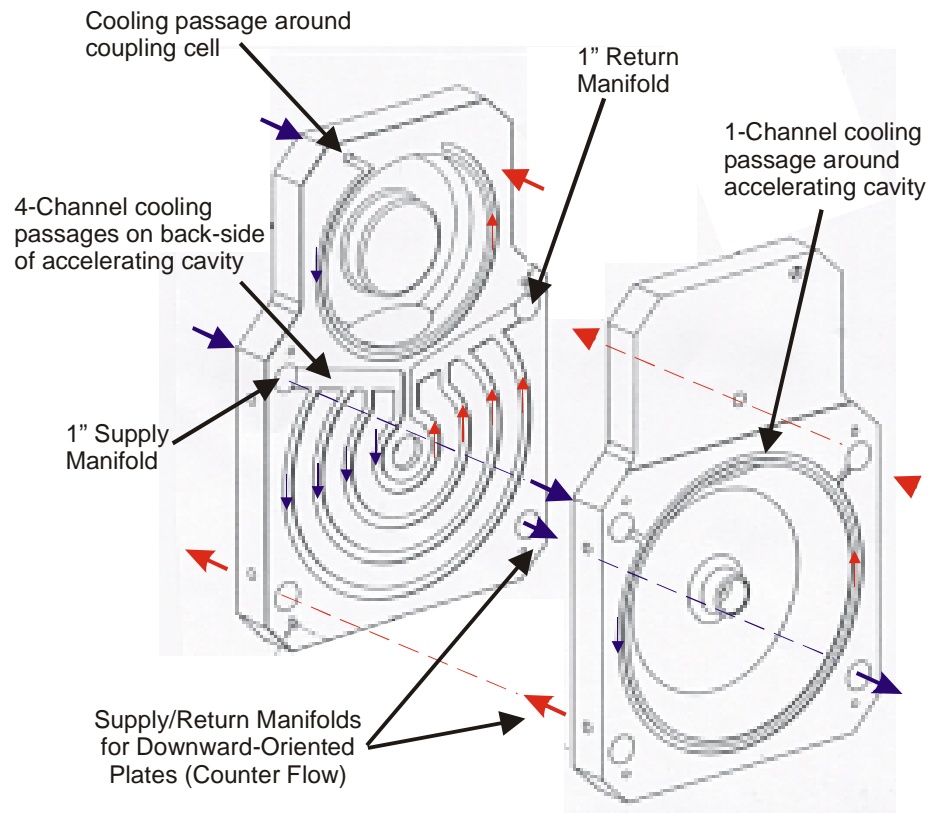

Figure 2. Water Cooling Channels and Internal Flow Manifolds. 


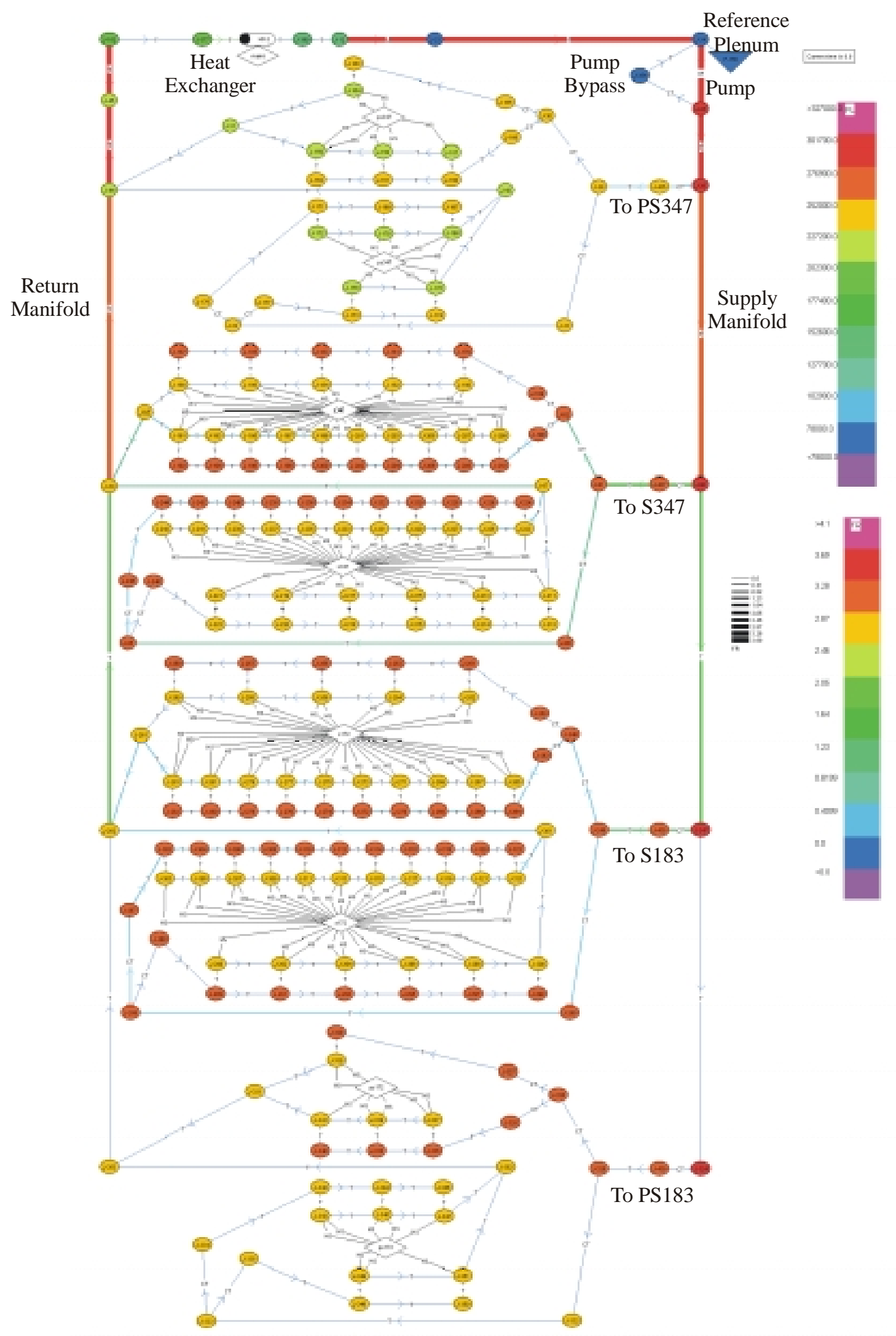

Figure 3. SINDA/FLUINT Diagram of Primary Cooling Loop. 




Figure 4. SINDA/FLUINT Diagram of Secondary Cooling Loop. 


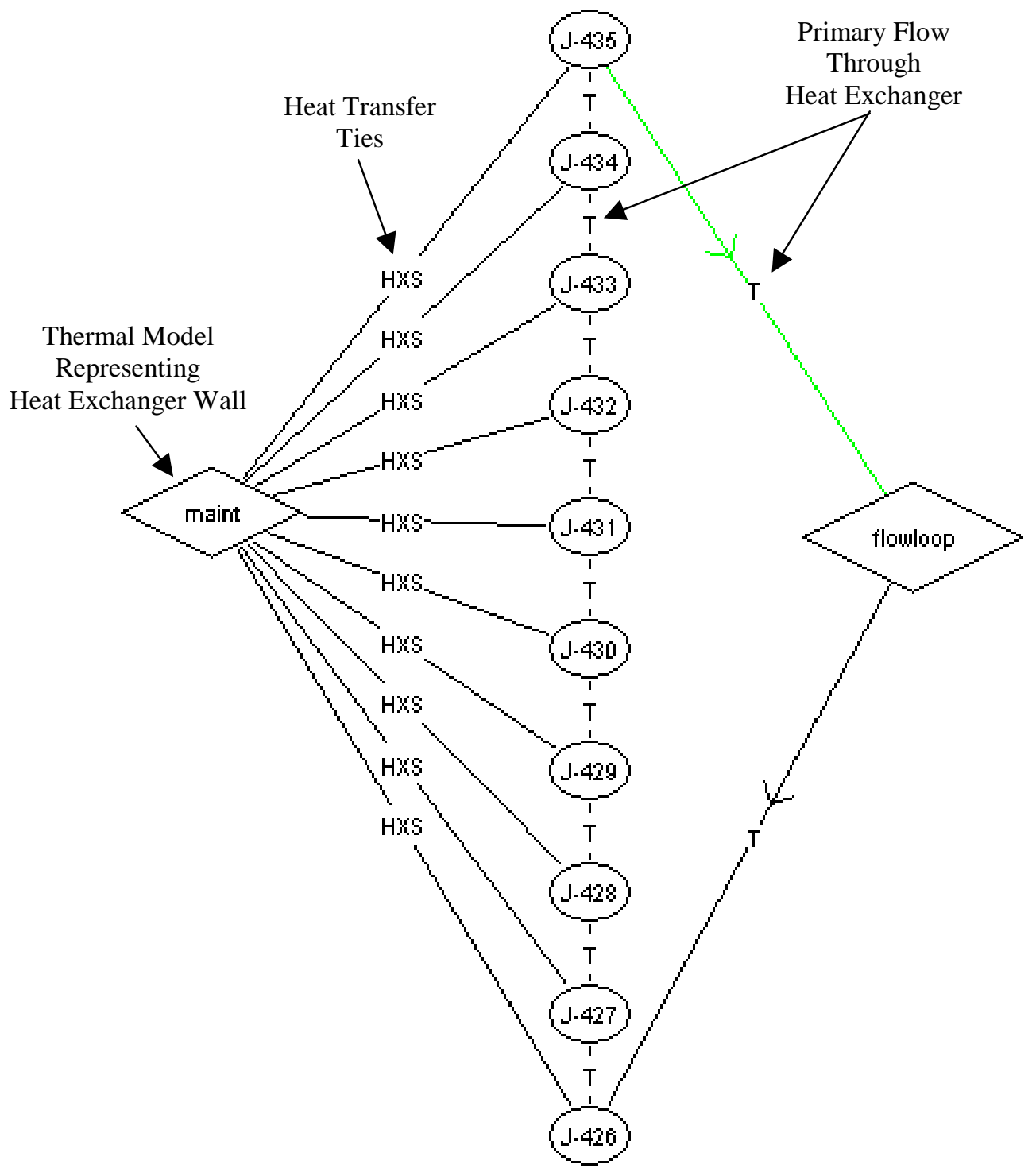

Figure 5. SINDA/FLUINT Diagram of Heat Exchanger 2 Macro. 


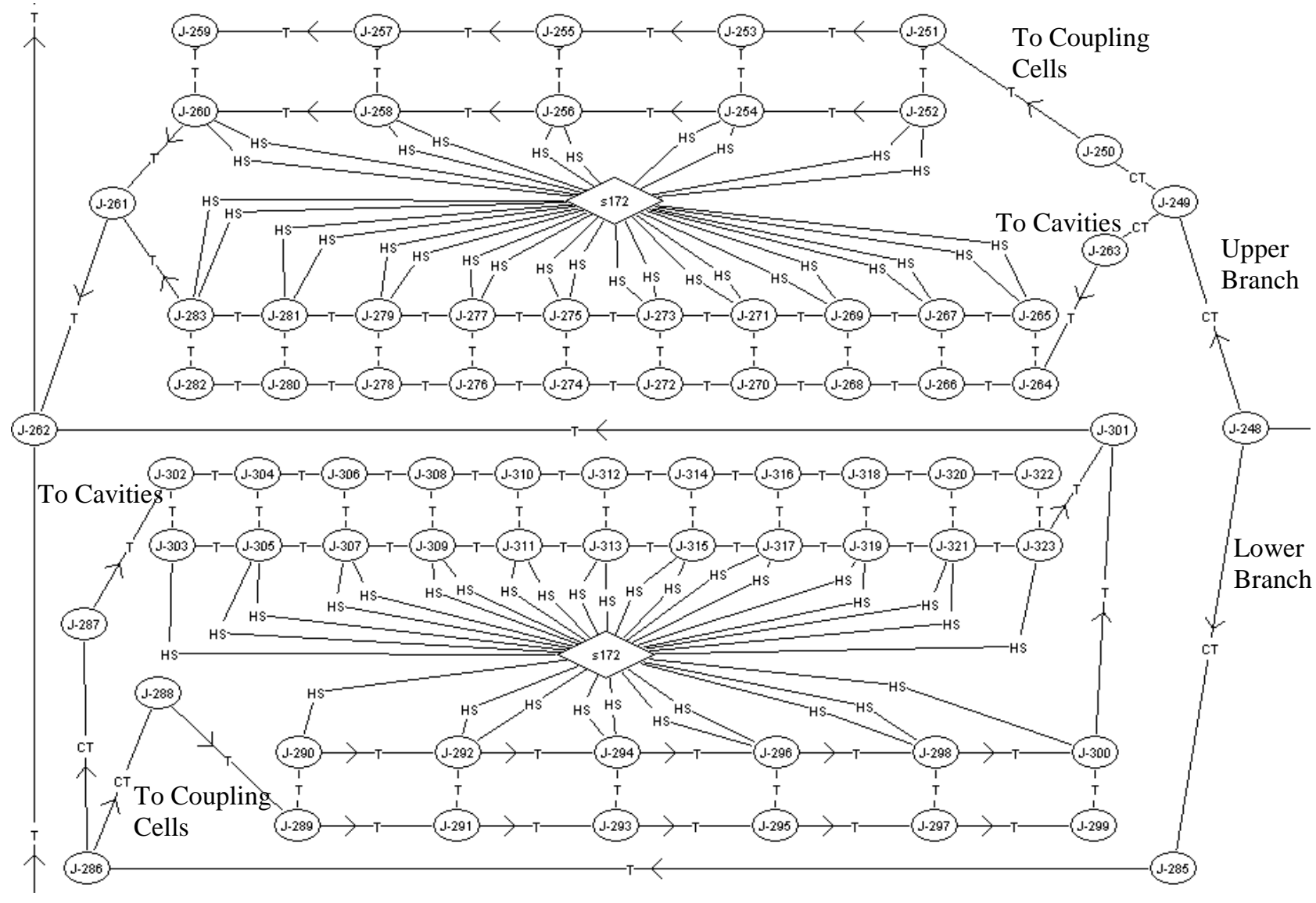

Figure 6. SINDA/FLUINT Diagram of Segment 183.
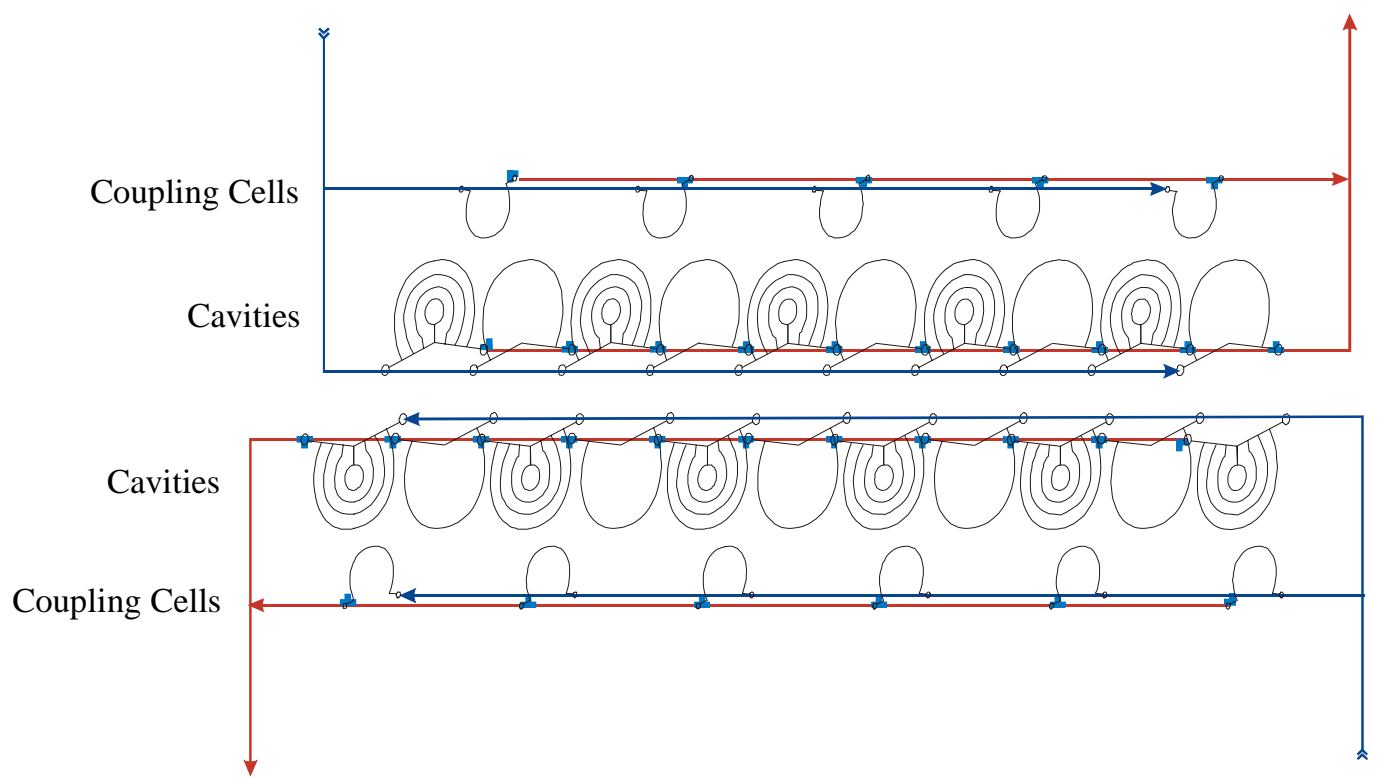

Figure 7. Alternating Arrangement of Accelerator Cavity 4- and 1-Channel Pairs and CouplingCell Cooling Chanels in Segment 183. 


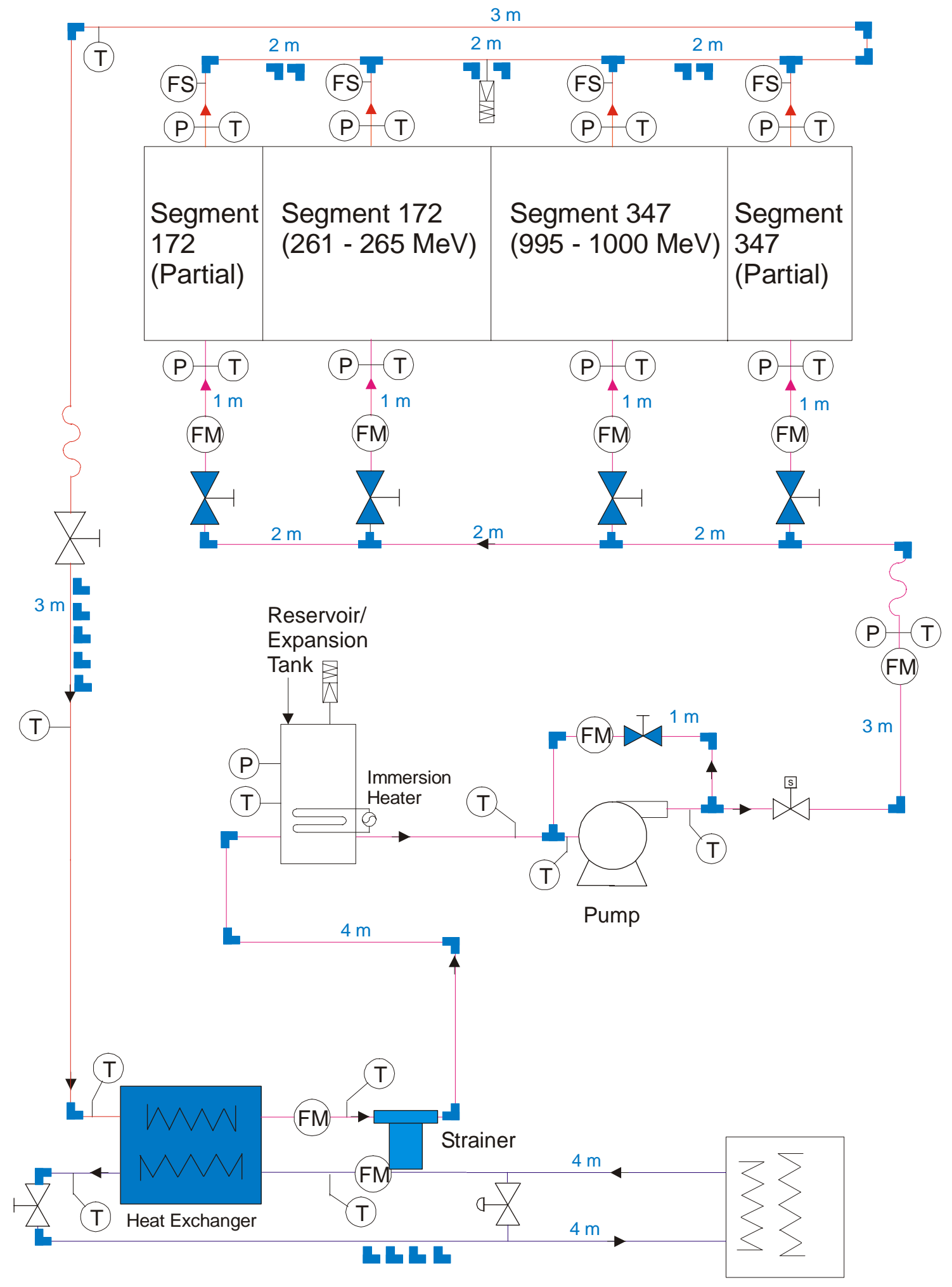

Figure 8. Pipe Lengths, Elbows, Tees, and Valves Modeled in Primary Loop. 


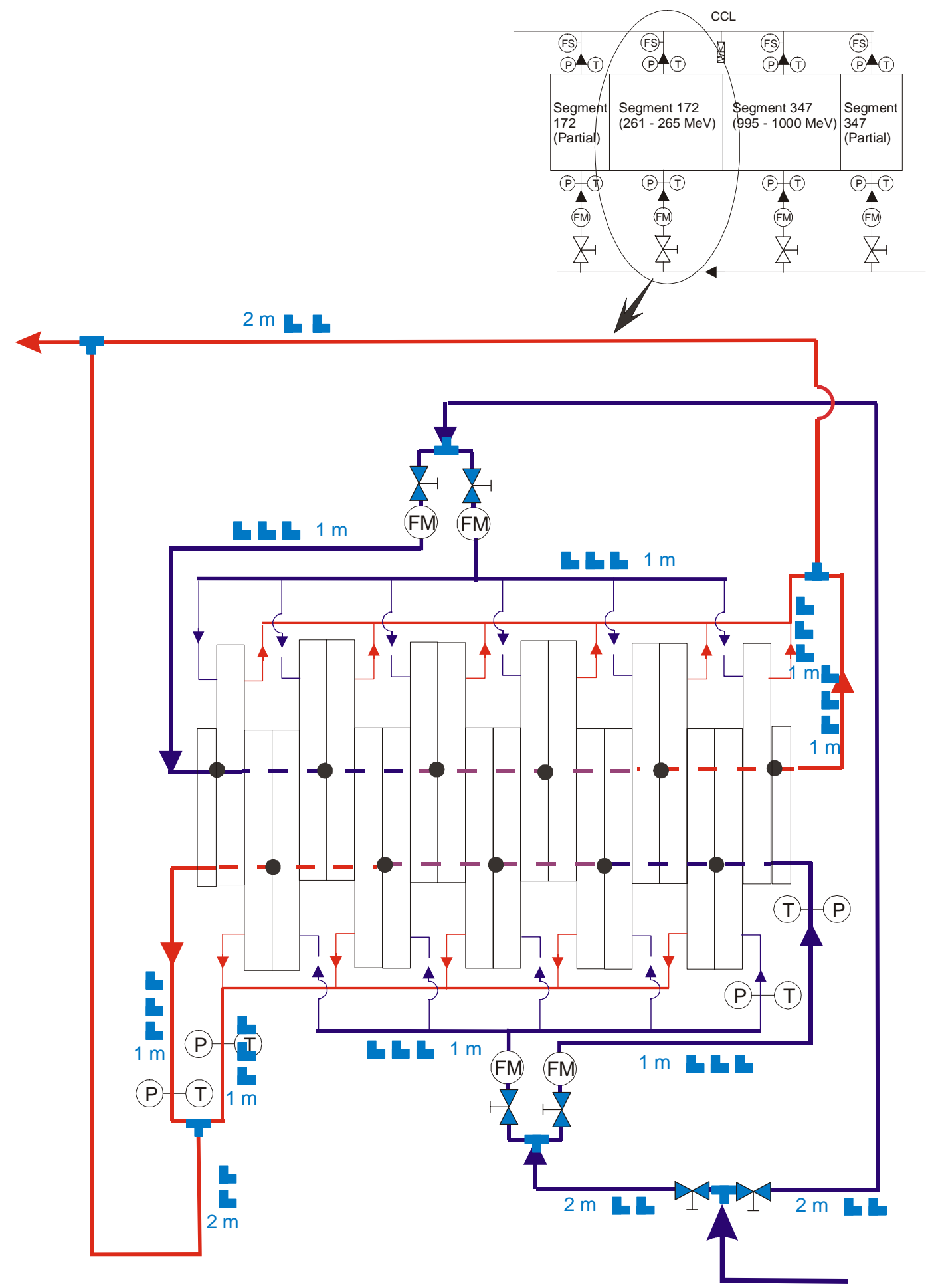

Figure 9. Pipe Lengths, Elbows, Tees, and Valves Modeled in Segment. 


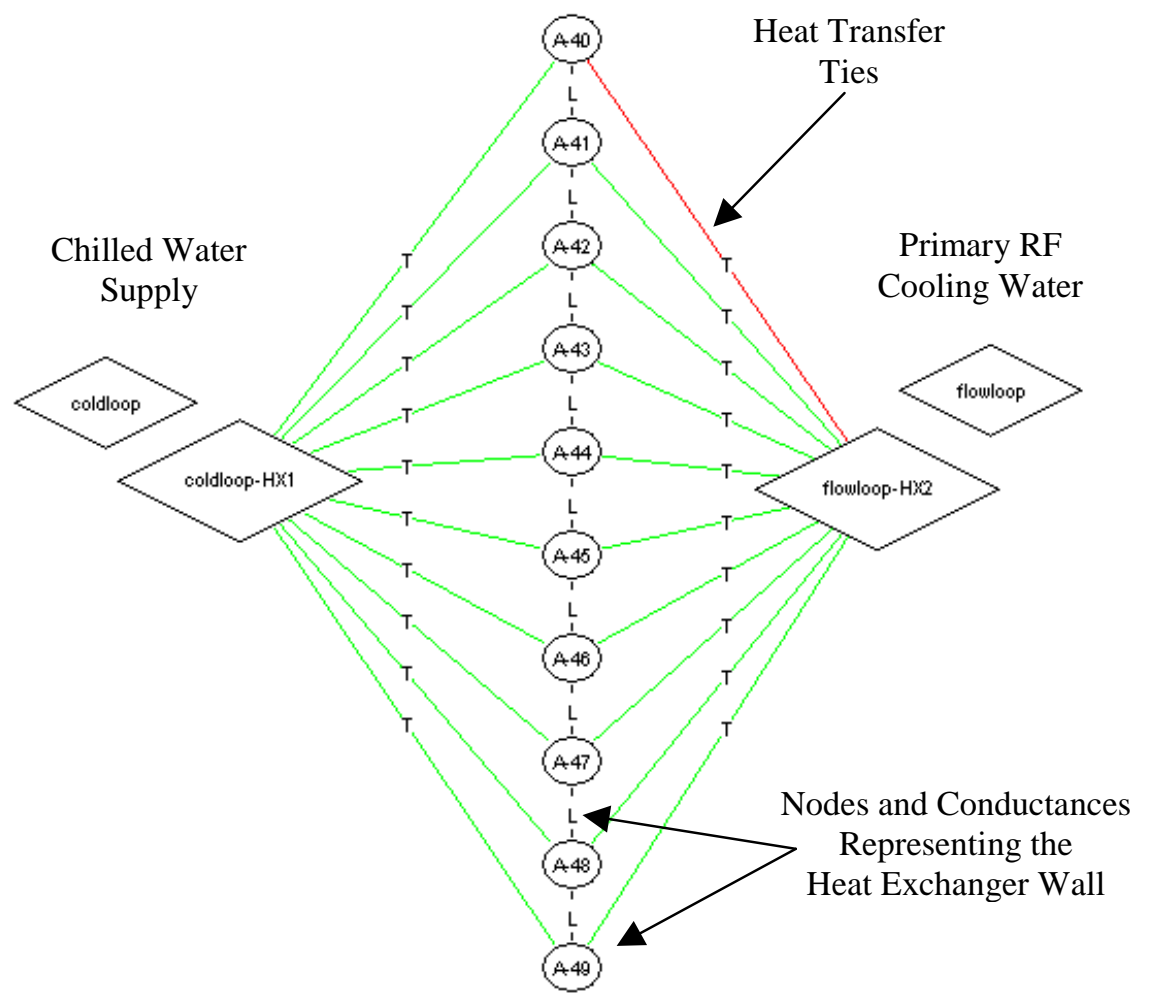

Figure 10. SINDA/FLUINT Diagram of Maint Thermal Submodel.

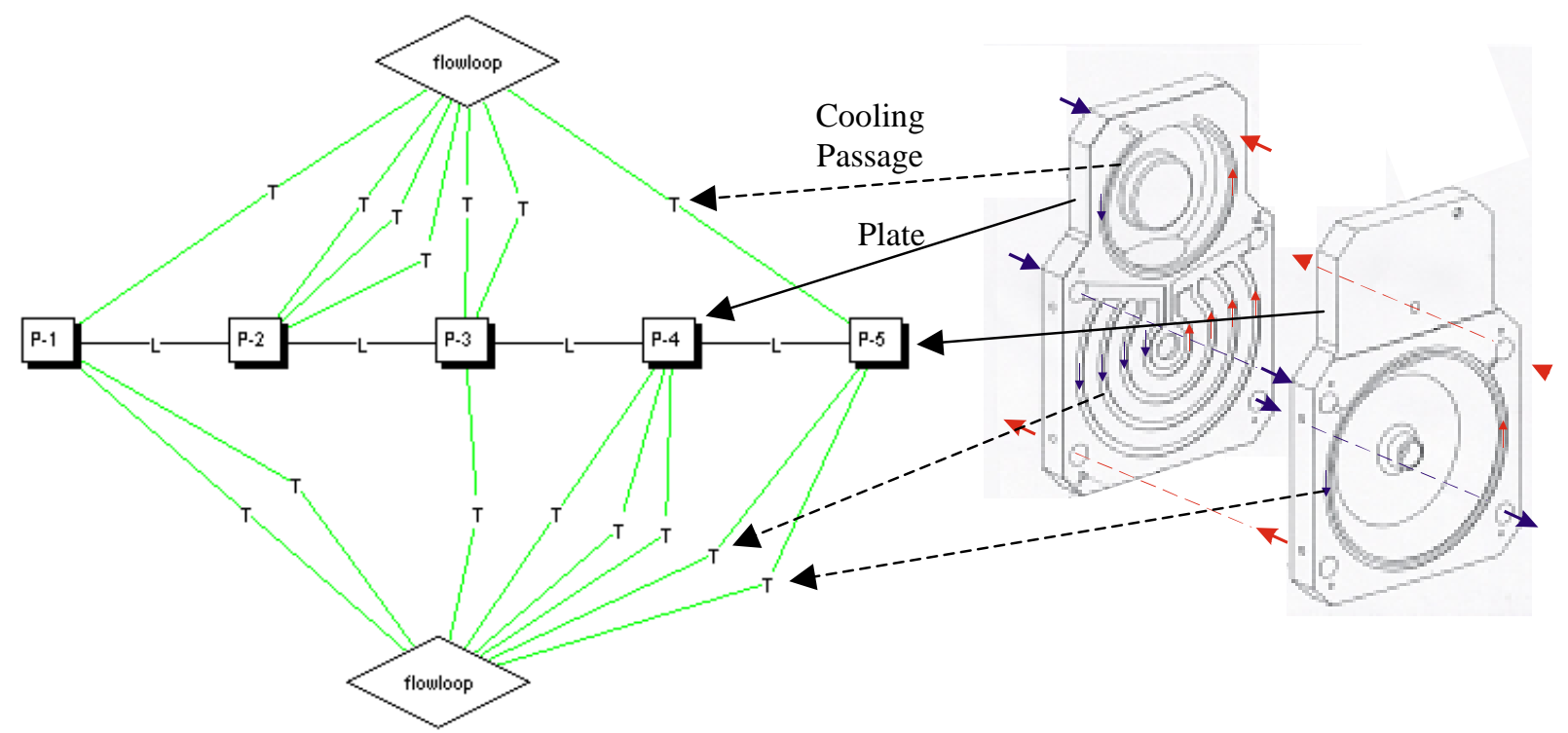

Figure 11. SINDA/FLUINT Diagram of PS347 Thermal Submodel. 


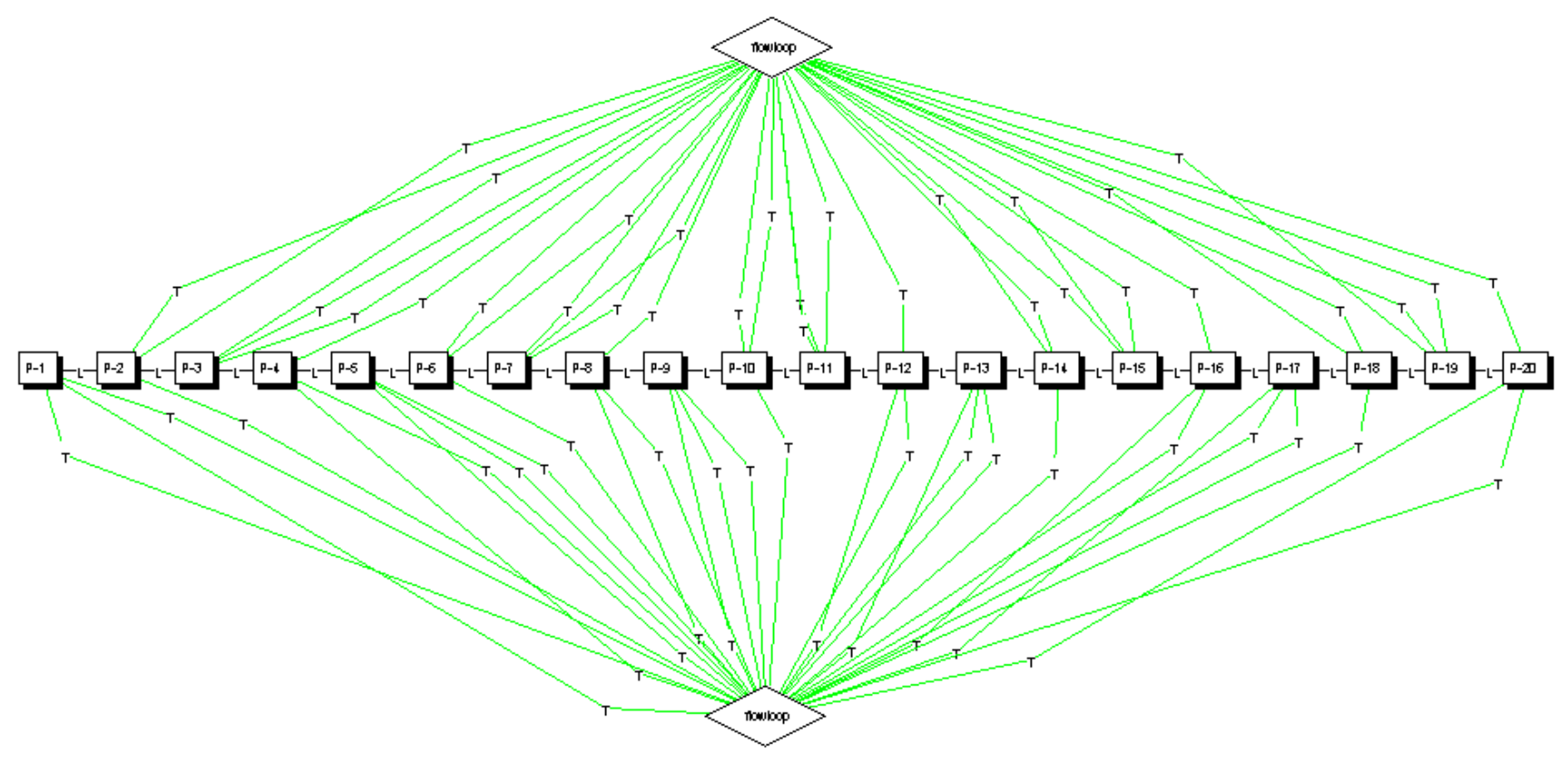

Figure 12. SINDA/FLUINT Diagram of S347 Thermal Submodel.

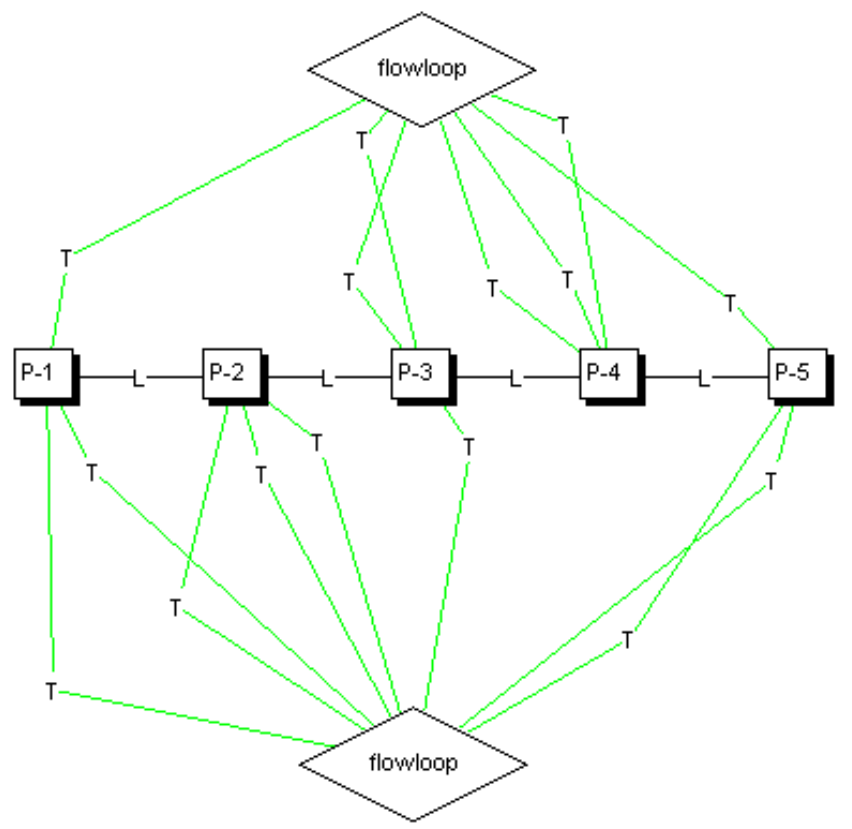

Figure 13. SINDA/FLUINT Diagram of PS172 Thermal Submodel. 


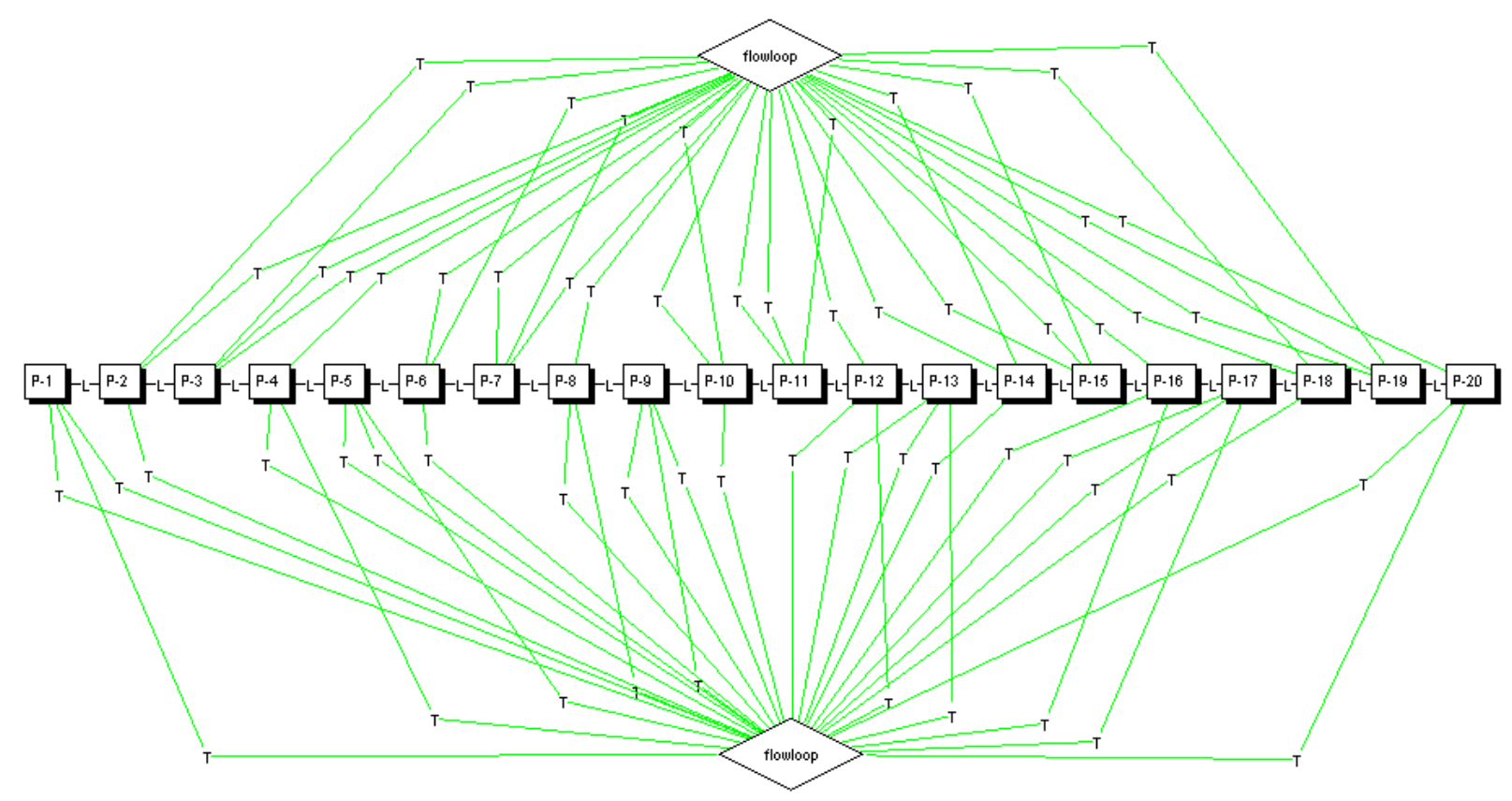

Figure 14. SINDA/FLUINT Diagram of S172 Thermal Submodel. 


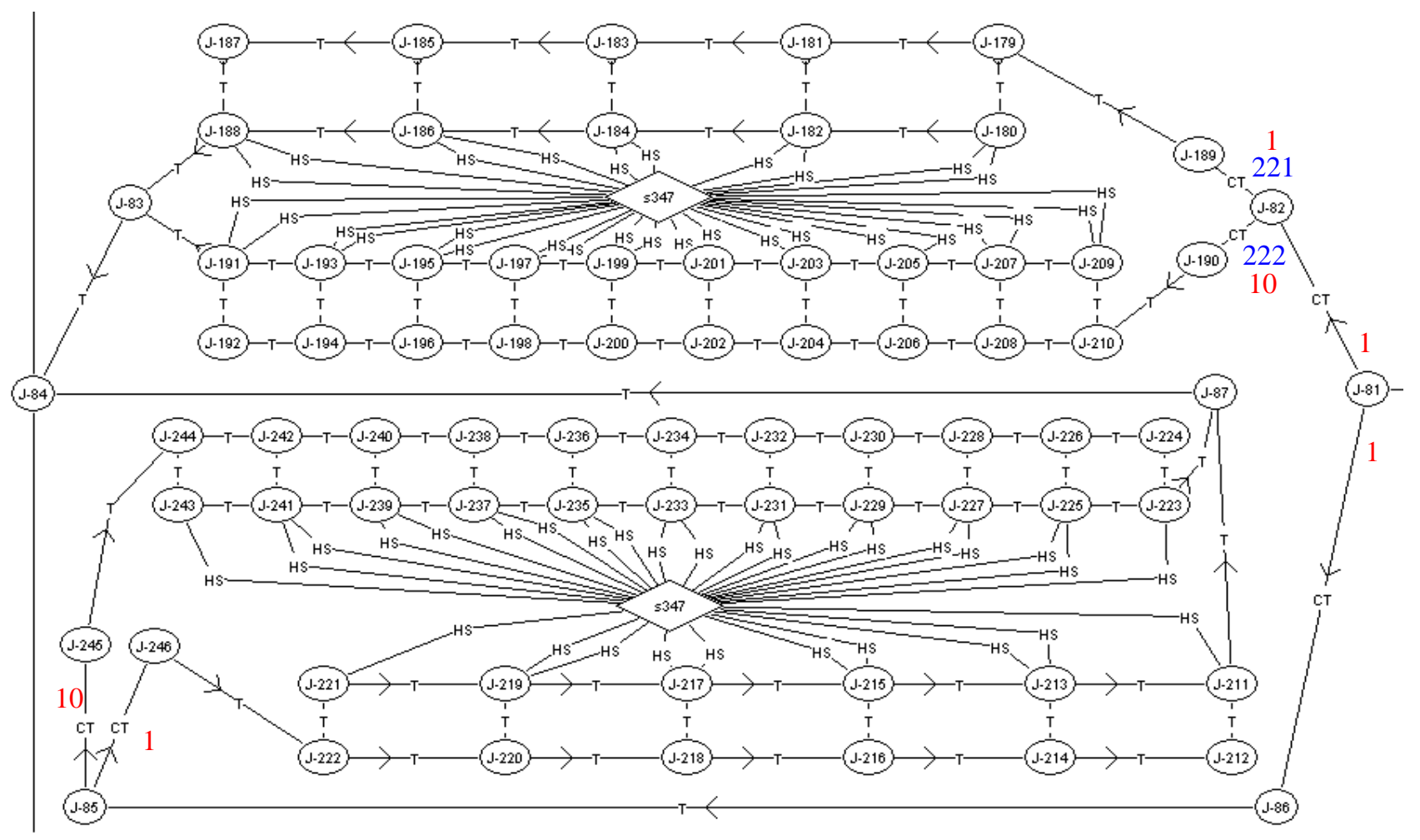

Figure 15. Segment Diagram Showing Flow Splits (in red) and valve numbers (in blue). 




Figure 16. Pressure Drop vs. Line Size for the Main Flow Loop. 


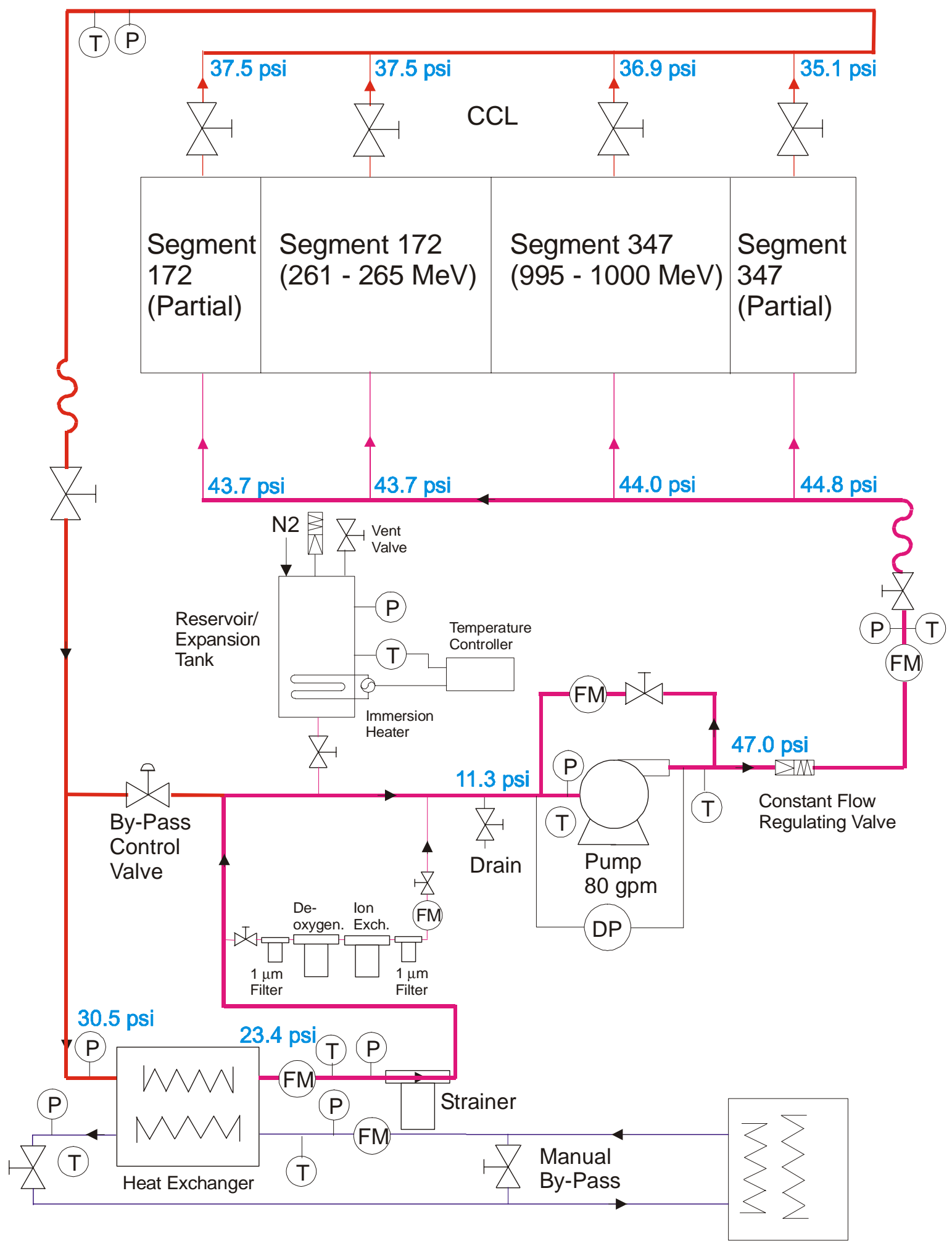

Figure 17. Flow Loop Schematic. 


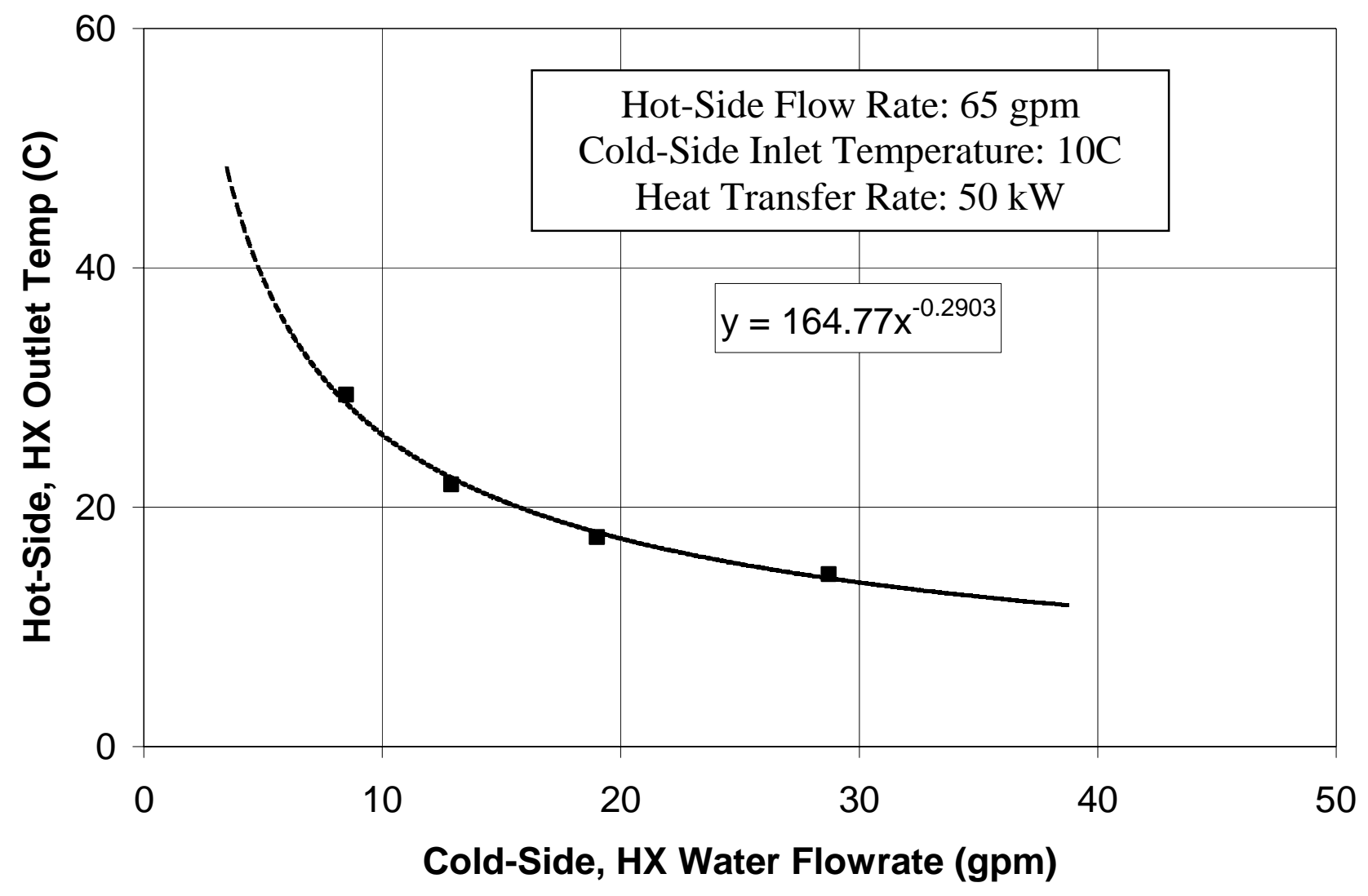

Figure 18. Temperature Control - Cold-Side Flow Variation. 


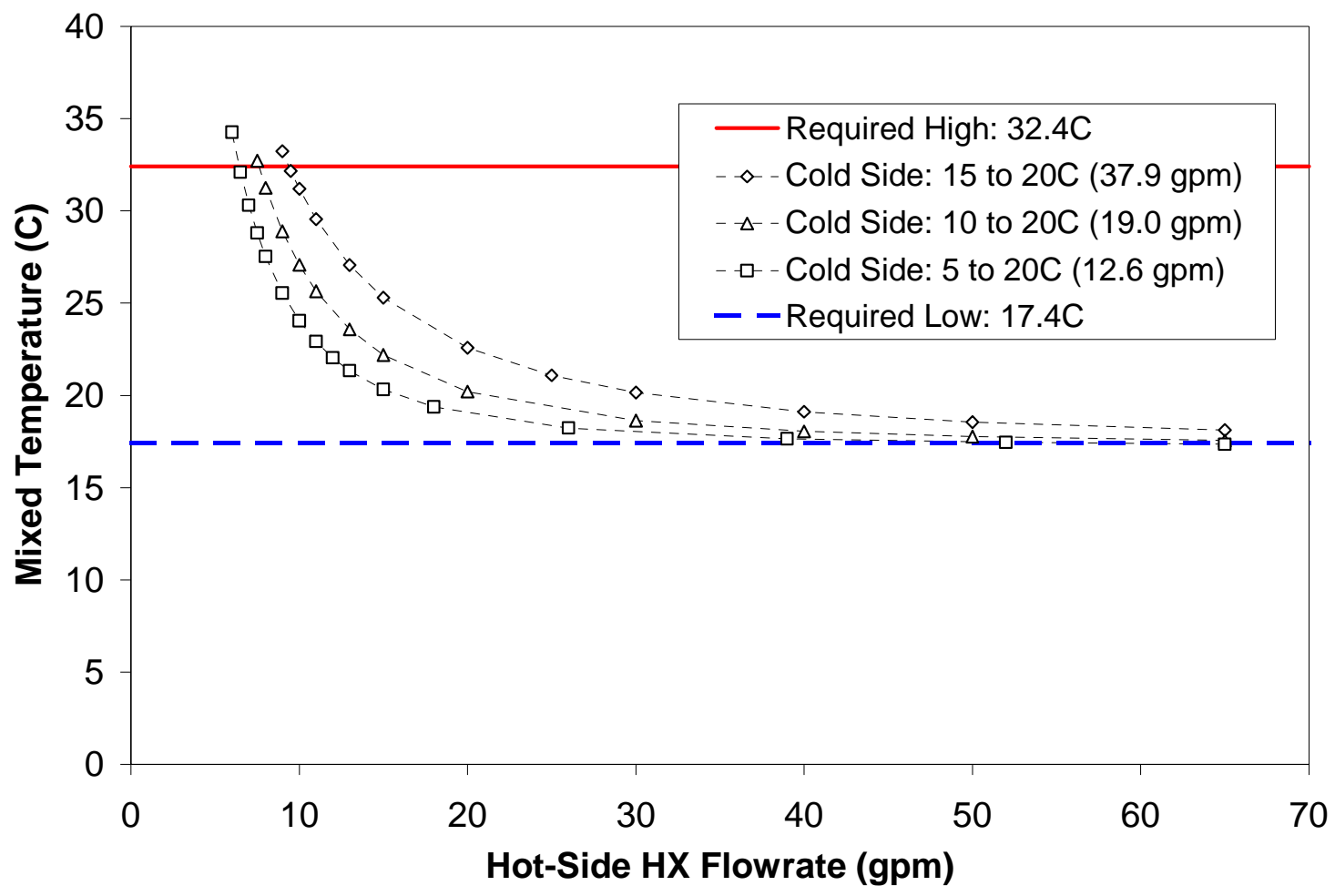

Figure 19. Temperature Control - Hot-Side Flow Variation: 2-Valve.

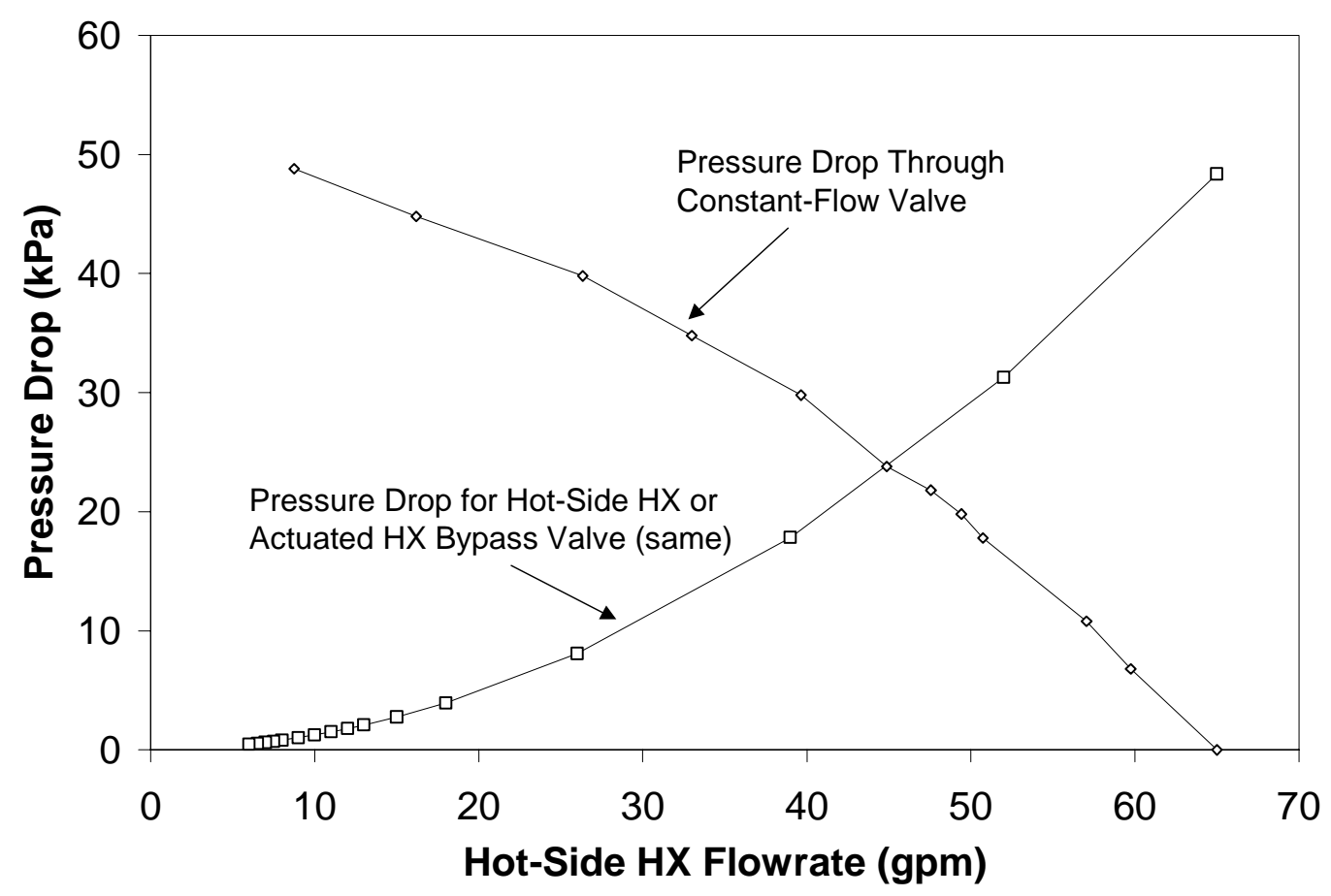

Figure 20. Pressure Drop - Hot-Side Flow Variation: 2-Valve. 


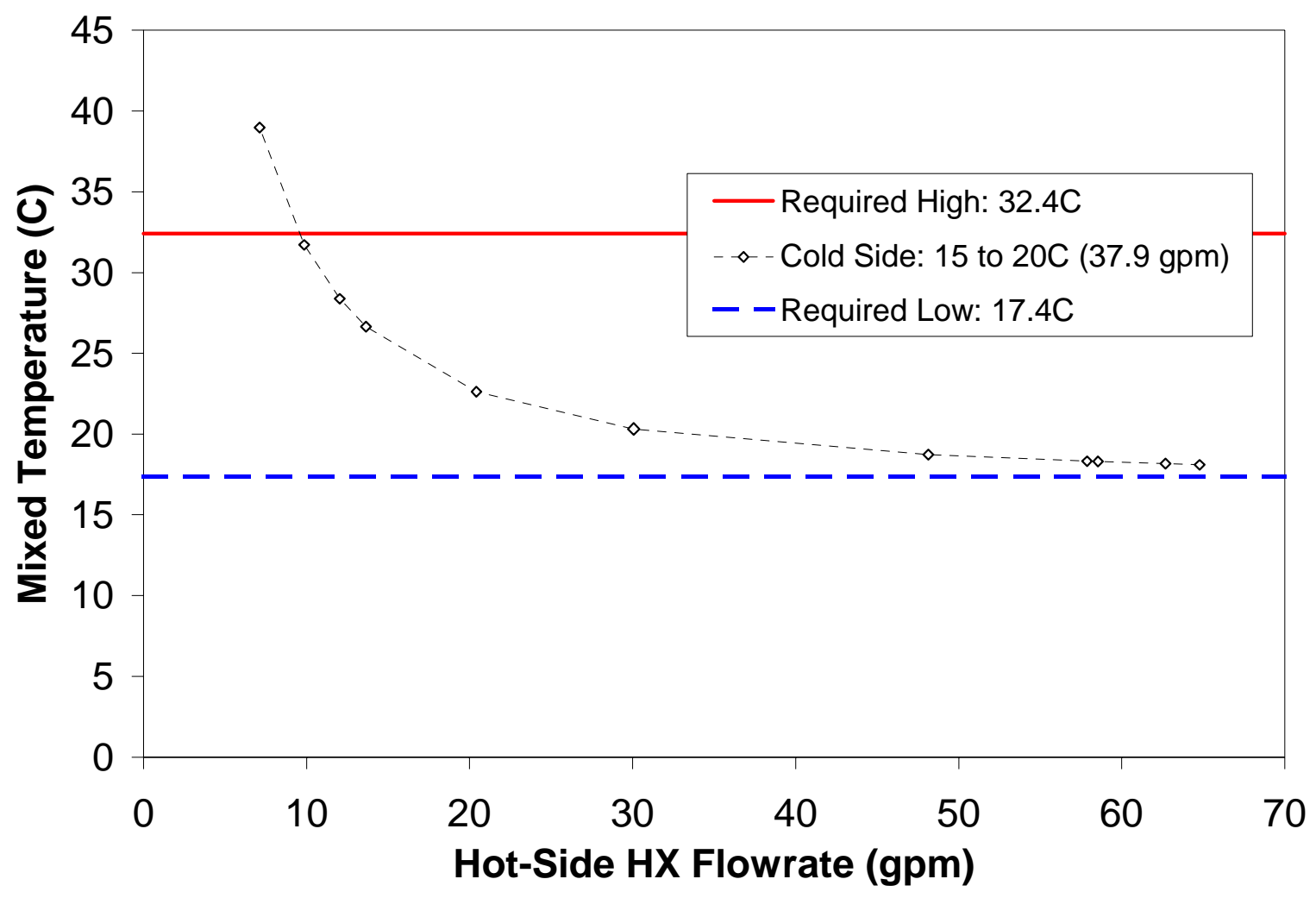

Figure 21. Temperature Control - Hot-Side Flow Variation: 1-Valve.

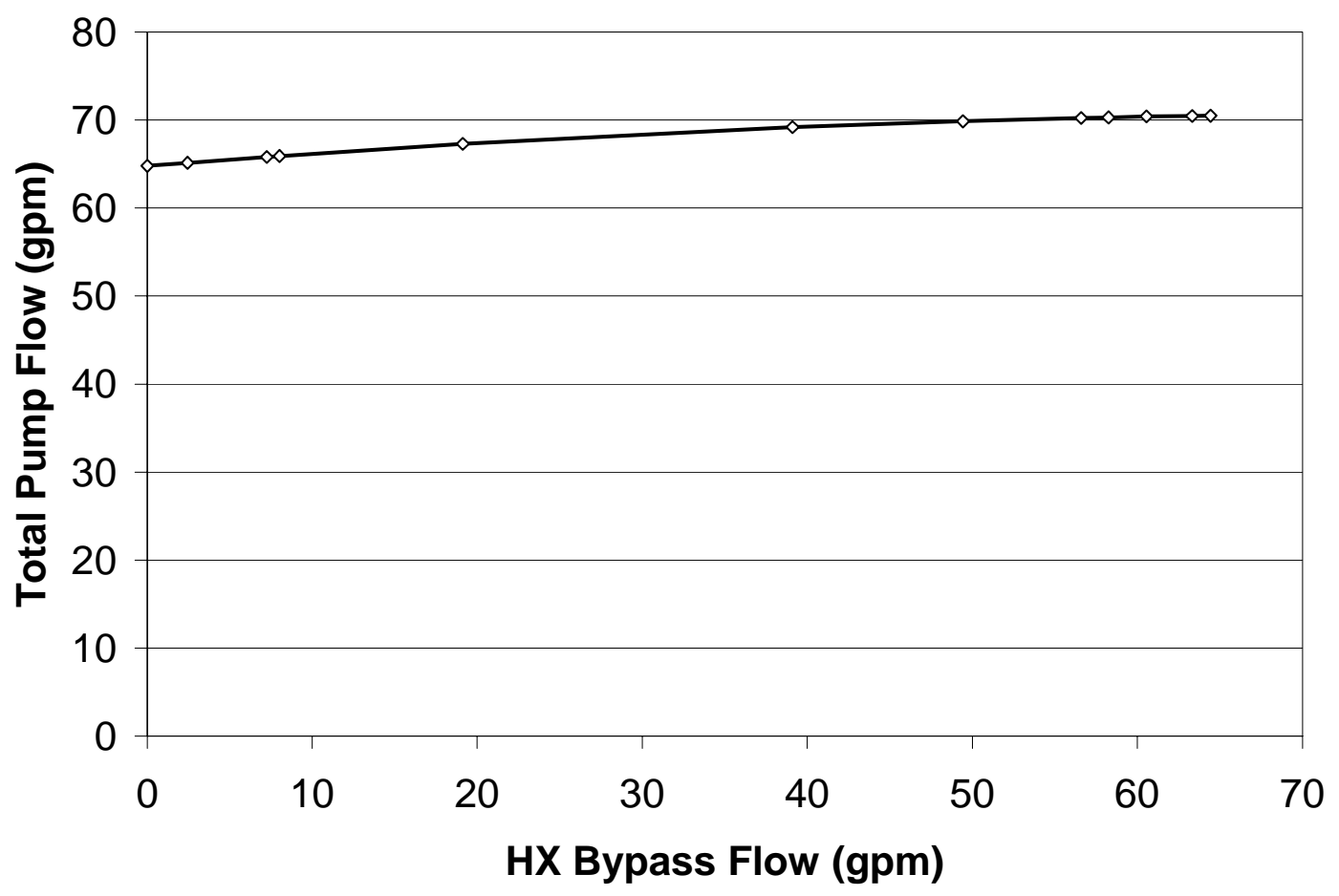

Figure 22. Total Flow Rate - Hot-Side Flow Variation: 1-Valve. 

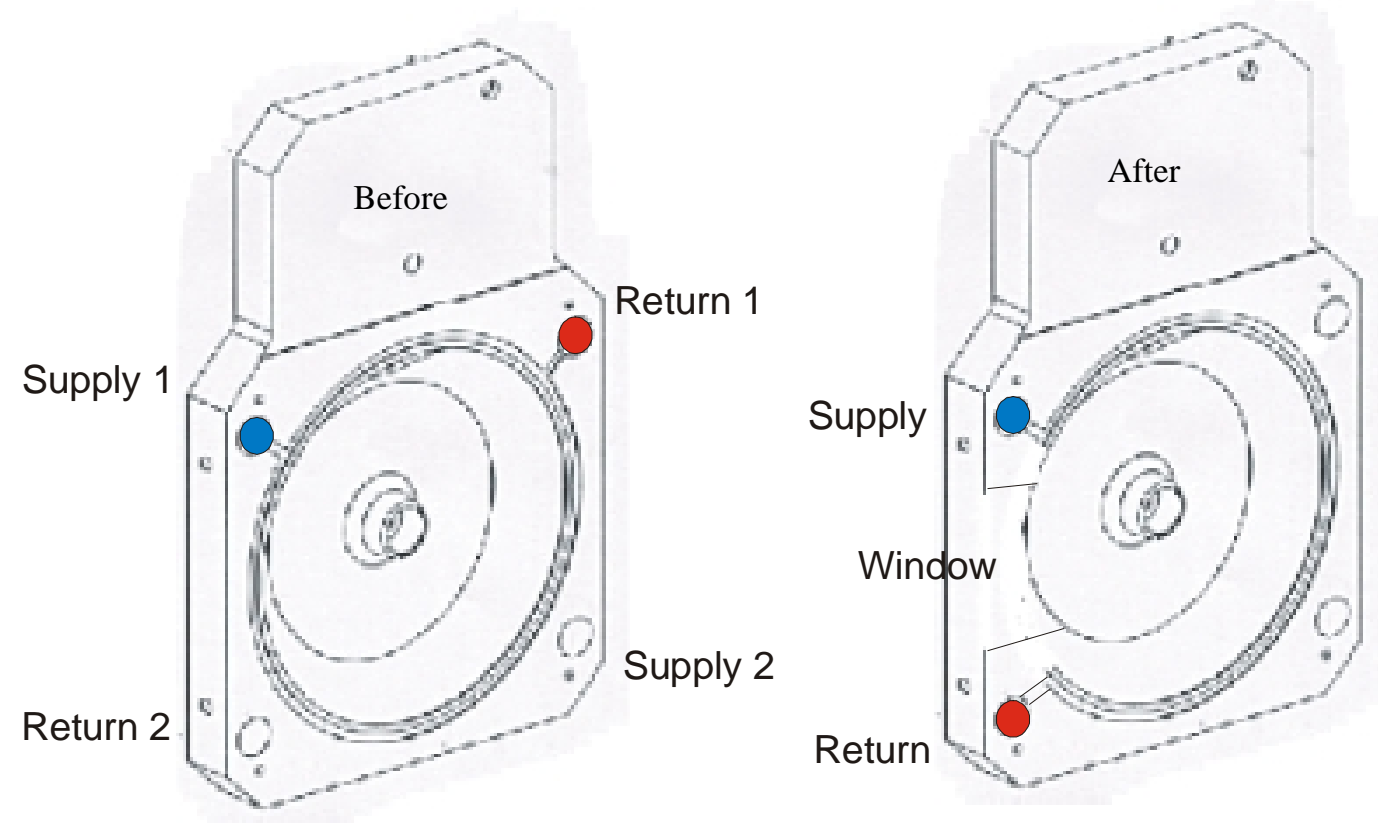

Figure 23. Cross-Manifolding Due to RF Window Location.

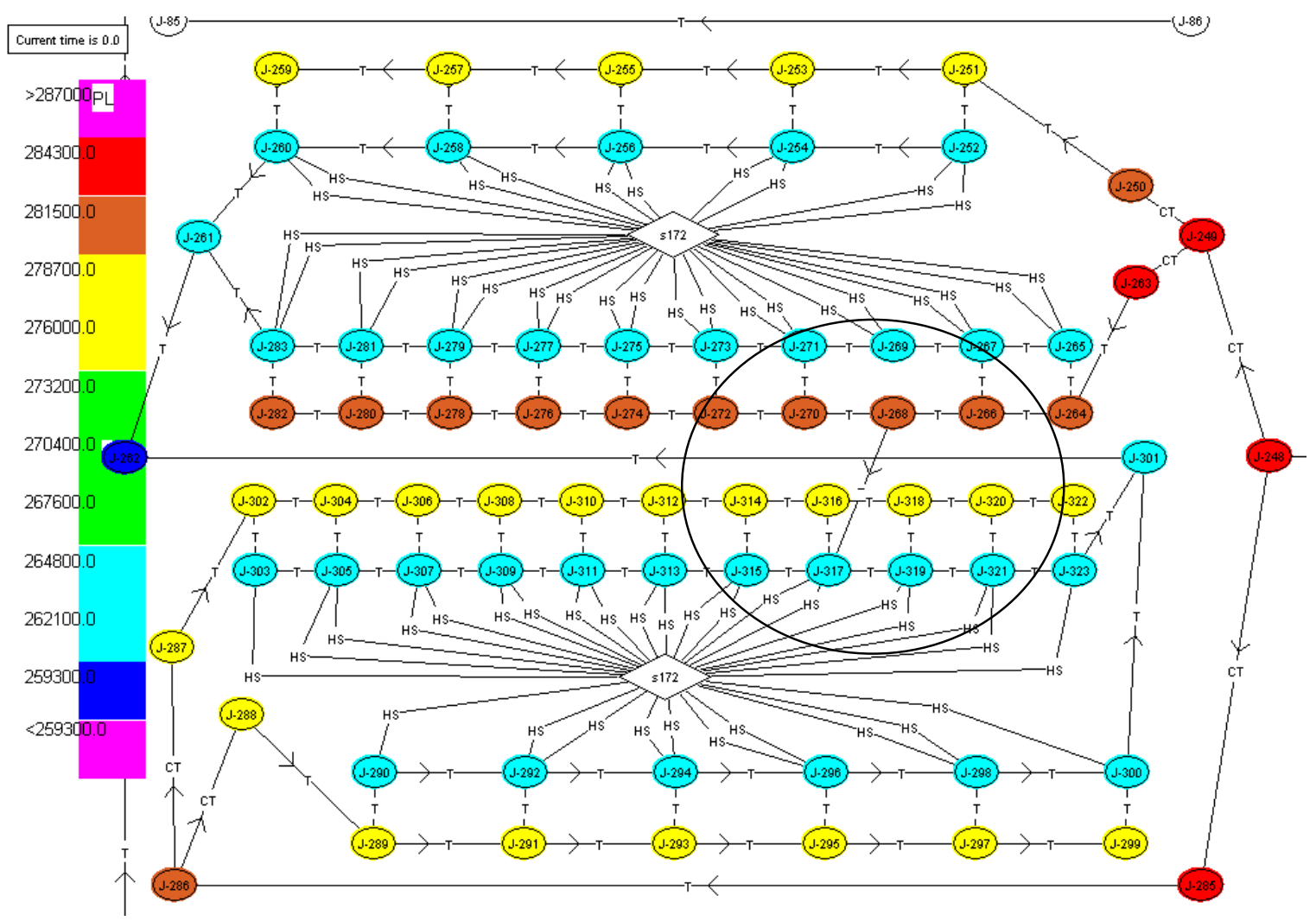

Figure 24. SINDA/FLUINT Diagram Showing Cross-Coupled Manifolds. 


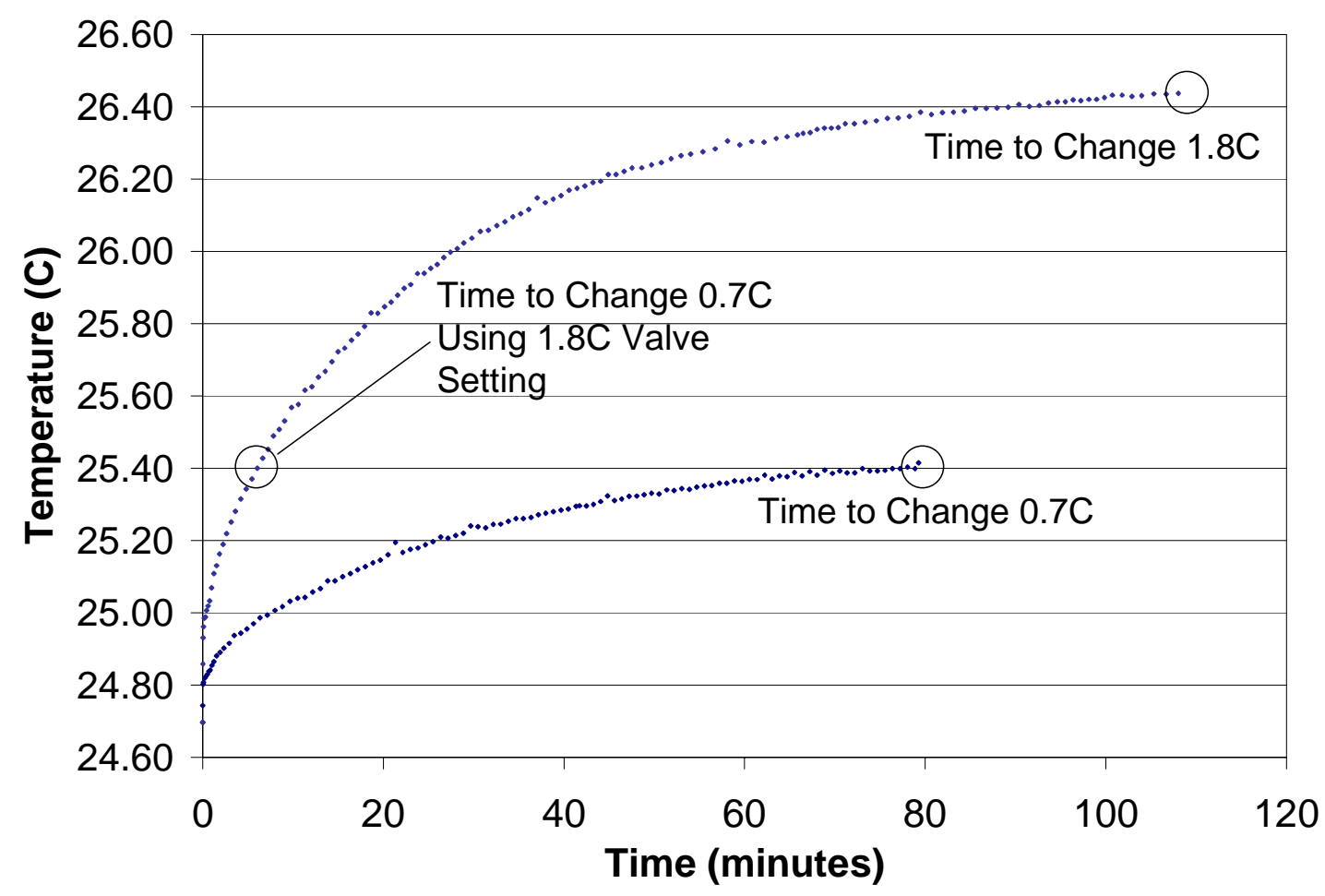

Figure 25. Transient Temperature Response Times.

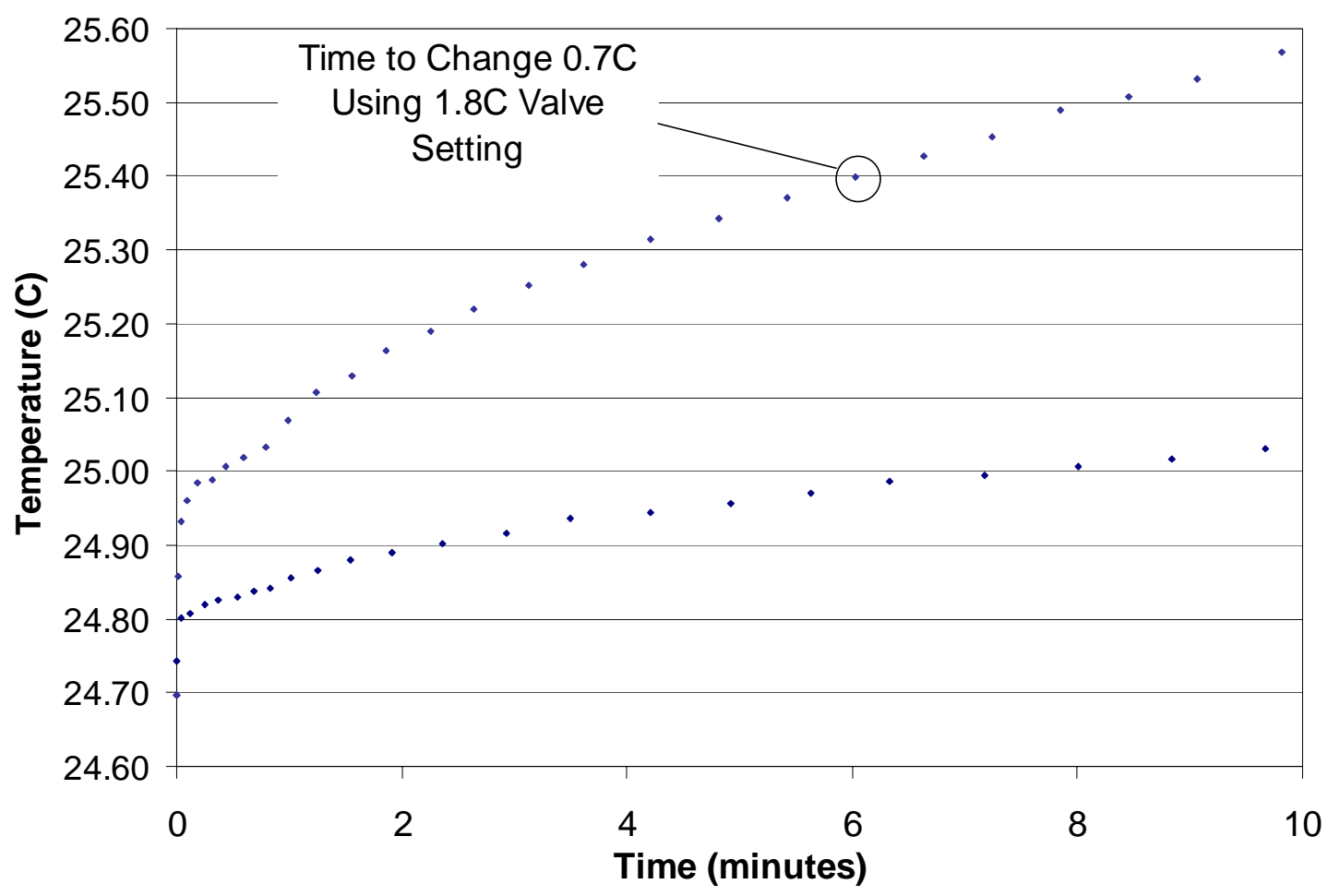

Figure 26. Transient Temperature Response Times, Enlarged View. 